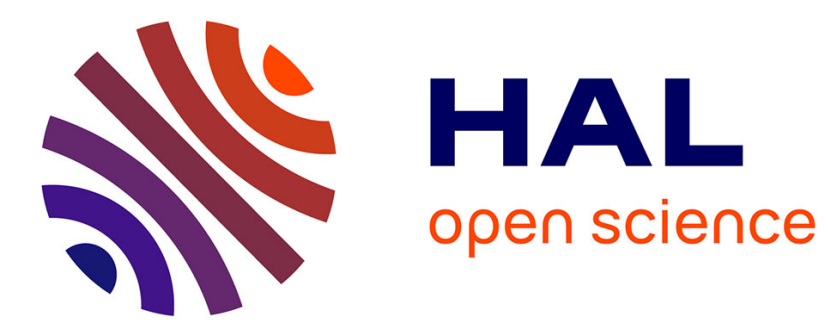

\title{
Migration of fluid-induced seismicity reveals the seismogenic state of faults
}

Louis de Barros, Nicolas Wynants-morel, Frédéric Cappa, Philippe Danré

\section{To cite this version:}

Louis de Barros, Nicolas Wynants-morel, Frédéric Cappa, Philippe Danré. Migration of fluid-induced seismicity reveals the seismogenic state of faults. Journal of Geophysical Research: Solid Earth, In press, 126 (11), pp.e2021JB022767. 10.1029/2021JB022767 . hal-03433200

\section{HAL Id: hal-03433200 \\ https://hal.science/hal-03433200}

Submitted on 17 Nov 2021

HAL is a multi-disciplinary open access archive for the deposit and dissemination of scientific research documents, whether they are published or not. The documents may come from teaching and research institutions in France or abroad, or from public or private research centers.
L'archive ouverte pluridisciplinaire HAL, est destinée au dépôt et à la diffusion de documents scientifiques de niveau recherche, publiés ou non, émanant des établissements d'enseignement et de recherche français ou étrangers, des laboratoires publics ou privés. 


\title{
Migration of fluid-induced seismicity reveals the seismogenic state of faults
}

\author{
Louis De Barros ${ }^{1, *}$, Nicolas Wynants-Morel ${ }^{1}$, Frédéric Cappa ${ }^{1,2}$, Philippe Danré ${ }^{1}$ \\ ${ }^{1}$ Université Côte d'Azur, CNRS, Observatoire de la Côte d'Azur, IRD, Géoazur, 06560 Sophia Antipolis, France \\ ${ }^{2}$ Institut Universitaire de France, Paris, France \\ * Corresponding author: debarros@geoazur.unice.fr (Louis De Barros)
}

\begin{abstract}
Seismic swarms, in natural contexts or induced by anthropogenic fluid-injections, commonly show migrations of earthquake hypocenters. Classically, such migrations are interpreted as the diffusion of the fluid pressure. However, recent studies show that the seismic front maps the stress concentration at the tips of propagating aseismic slip that is primarily induced by the fluid pressure increase. In this case, seismic migration might depend on the hydromechanical properties that control the dynamics of aseismic slip propagation rather than the hydraulic diffusivity. Here, we use synthetic seismic catalogs obtained from the hydromechanical modelling of a slip-weakening, permeable fault response to a fluid-injection. By varying the fault permeability and the stress state, we show that the shape of the seismic front in a distance-time plot depends on the initial fault criticality to failure, and not on the hydraulic properties. We then extrapolate this numerical result to seven observed injection-induced earthquake swarms by showing that the shape of the migration front directly depends on the seismogenic index. The seismic front has a diffusive behavior when the aseismic slip is directly driven by the pressure increase, either at the swarm beginning or later if the faults are not initially critically stressed. On the contrary, an accelerating seismic front indicates a high-criticality stressed fault, on which the aseismic slip runs away from the fluid pressurized area. Therefore, this study highlights that the seismic front shape may prove a useful indicator to characterize the initial stress state of faults over which the swarms occur.
\end{abstract}

\section{Plain language summary}

The seismicity induced by anthropogenic fluid-injections or during natural swarms commonly migrates with time. This migration has been classically interpreted as due to the fluid-pressure diffusion. However, recent models show that fluid injections first induce an aseismic slip that then triggers seismicity at its tips through stress concentrations. Indeed, using seismo-hydro-mechanical modellings, we show that the seismic front follows the aseismic slip front, which can be ahead or behind the fluid pressure front. Therefore, the seismic migration depends on the parameters that control the aseismic slip, and particularly, on how close from failure is the stress state of the fault. Comparing those numerical results to catalogs of induced seismicity in geothermal reservoirs, we show that the shape of the migration in distance-time plots can be used to monitor the seismogenic state of a reservoir. This revised interpretation of the seismic migration can then prove useful to anticipate if the swarm may evolve toward large earthquakes or not. 


\section{Key words}

Induced seismicity; seismic migration; fault criticality

\section{Key Points}

- Fluid-induced seismicity is triggered by stress concentrations at the tips of a fluid-induced aseismic slip

- Seismic migration does not follow a hydraulic diffusion, as it is accelerating depending on the fault criticality toward the stress state

- The shape of the seismic front in a distance-time plot is a probe for the seismogenic state of a reservoir

\section{Introduction}

Seismic swarms are made up of numerous small-to-moderate earthquakes clustered both in time and in space. Contrary to classical mainshock-aftershock sequences, there is no distinguishable event with a magnitude much larger than the other ones at the beginning of the sequence. Seismic swarms are observed in a wide variety of geological contexts, with either high-deformation rates, such as in Corinth Gulf (De Barros et al., 2020; Duverger et al., 2018) or very limited ones, e.g. in Western Alps (Daniel et al., 2011), or in Bohemia/Vogtland (Fischer and Hainzl, 2021). They are also commonly observed along creeping faults (Gualandi et al., 2017; Lohman and McGuire, 2007) and in subduction areas (Nishikawa and Ide, 2017; Vallée et al., 2013). The exploitation of subsurface reservoirs, associated with injection or extraction of fluids, also induced seismic swarms (Cornet, 2016; Ellsworth, 2013; Keranen and Weingarten, 2018). For example, deep geological storage of large volumes of waste-water made Oklahoma the US state with the highest seismic activity in 2016 (Yeck et al., 2017). Geothermal activity also caused earthquakes, as shown by the different injections experiments in Soultz-sous-Forêts, France (Cauchie et al., 2020; Charléty et al., 2007) and in Basel, Switzerland (Herrmann et al., 2019), or more recently with the 2017 Pohang earthquake in South Korea (Grigoli et al., 2018). As seismic swarms may last for days or even for years, a driving process is required to maintain such activity. Previous studies have shown that this mechanism can be either a fluid pressure perturbation (Chen et al., 2012; Daniel et al., 2011; Parotidis et al., 2003), a slow and aseismic deformation (Gualandi et al., 2017; Lohman and McGuire, 2007; Vallée et al., 2013) or an interplay between them (Bourouis and Bernard, 2007; Cornet 2016; De Barros et al., 2020, 2018; Guglielmi et al., 2015; Hatch et al., 2020). However, differentiating the contribution of fluids versus mechanical stressing is usually ambiguous, and still under debate (Hainzl, 2004; Vidale and Shearer, 2006). Thus, it is important to understand the conditions that control the seismic swarms in order to anticipate their evolution.

In both natural and injection-induced seismic swarms, a common feature is the migration of the seismicity, as the seismic cloud is usually observed to expand with time. To analyze such migrations, analytical models have been developed to link the distances $R$ of earthquake hypocenters relative to an origin position with the elapsed time $t$, in the so-called $R-t$ plot (Shapiro et al., 1997). The origin time and position can be defined as the source of the perturbation that drives the swarm. As the latter is usually unknown, it can be approximated by the position and time of the first events. In the $R-t$ plot, the seismicity envelope is the 
curve that links the furthest events observed at each time. As it encloses all the seismic events, it then defines the seismic front, and its behavior may bring insights on the processes driving the swarms.

The most commonly used model to explain the growth of the seismic front is based on the fluid pressure diffusion in a homogeneous porous medium (Shapiro et al., 2002, 1997). It assumes that the seismicity is directly triggered by the decrease of the effective normal stress acting on a fault in response to the fluid pressure increase. Thus, the seismic front exactly maps the extent of the area where the fluid pressure is above a failure threshold. Therefore, in this model, it corresponds to the fluid pressure front, and both fronts follow a diffusive law, whose simplest theoretical solution for a point pressure source is given by:

$$
R=\sqrt{4 \pi D t}
$$

where $R$ is the distance of seismic events $(\mathrm{m})$ relative to the pressure source, $t$ is the elapsed time $(\mathrm{s})$, and $D$ is a diffusivity $\left(\mathrm{m}^{2} / \mathrm{s}\right)$ of the medium. In this framework, $D$ is assumed to be a hydraulic diffusivity. From the analysis of the migration within several seismic swarms worldwide, the estimated values of diffusivity $D$ mainly range between 0.01 and $10 \mathrm{~m} / \mathrm{s}^{2}$ (e.g., Parotidis et al., 2003; Shapiro et al., 2002; Talwani et al., 2007). This model assumes that all failures are (1) seismic, (2) only triggered by fluid pressure increase, (3) thus, located in the pressurized area, and (4) that there is no coupling between fluid diffusion, fault failures and hydromechanical properties. Contrary to this purely hydraulic diffusion model, hydromechanical couplings were fully considered to explain seismic migration in the case of hydraulic fracture growth. In this case, the growth of $R$ with time $t$ may be either linear, square-root or cubic-root depending on the fracture geometries and the different mechanical assumptions (Dahm et al., 2010; Shapiro and Dinske, 2009).

Several studies have also shown that seismic swarms can be driven by slow, aseismic shear slip on faults rather than by a pure fluid diffusion process (De Barros et al., 2020; Hatch et al., 2020; Lohman and McGuire, 2007; Vidale and Shearer, 2006). Nonetheless, aseismic slip may be a triggered response to a perturbation. For example, large earthquakes are generally followed by afterslip that drives the aftershock sequences, and the seismic area expands as $R \propto \log (t)$ (Agurto-Detzel et al., 2019; Perfettini et al., 2018). Fluid pressure perturbations are also known to induce aseismic slip, which then triggers microseismicity through stress concentration developing at the tips of the expanding aseismic area (Cappa et al., 2019; De Barros et al., 2018; Guglielmi et al., 2015). In this case, the seismicity therefore migrates with the aseismic slip front (Bhattacharya and Viesca, 2019; Dublanchet, 2019; Wynants-Morel et al., 2020), which may or may not outpace the fluid pressure front. To model this seismic migration associated with aseismic slip, Bhattacharya and Viesca (2019) proposed that the seismic front expands as a hydraulic diffusion, but corrected by a factor $\lambda$, as $R \propto \lambda \sqrt{D t}$. This correcting factor depends on the criticality of the fault, which is the proximity of initial stress acting on the fault to failure. This factor allows the seismicity to migrate faster than the fluid in highly critical faults. Using a fully coupled seismo-hydromechanical modelling, Wynants-Morel et al. (2020) studied the response of a slipweakening, highly permeable fault to a fluid injection. They show that the aseismic front that triggers seismicity may not follow a diffusive shape, as it may slow down or accelerate compared to the fluid front. This change of seismic migration behavior depends on the fault criticality, and to a smaller extent to frictional fault properties (Wynants-Morel et al., 2021).

In summary, the seismic front migration has been generally explained by fluid pressure diffusion for more than 20 years. However, recent models of seismicity triggered by fluid-induced aseismic slips suggest that the 
migration is driven by the propagation of an aseismic deformation along the fault, and not by fluid diffusion. In the light of these recent models, we here aim at understanding better what controls the migration of the seismic front, and how to use this migration to infer fault and medium properties.

To respond to these questions, in this work, we first analyze seismicity migration in synthetic data. Building on the 3D modeling works from Wynants-Morel et al. $(2020,2021)$, we focus on the hydromechanical and seismological responses of a single, high-permeability and slip-weakening fault to fluid injection. Such modelling shows that the seismic migration is controlled by the propagation of an aseismic slip, and thus highlights a sensitivity to the criticality of the fault. We then extrapolate these findings to data of injectioninduced seismicity cases using the seismogenic index (Shapiro, 2018). Finally, we discuss how the shape of the seismic migration is a possible probe to monitor the seismogenic state of the fault.

\section{Synthetic seismic data and methods}

\subsection{Modelling principles and set-up}

We use a 3D Distinct Element Code (3DEC, Itasca Consulting Group, 2016) to model the response of a permeable, slip-weakening fault to a fluid injection (Wynants-Morel et al., 2020). The model is hydromechanically fully coupled, as fluid pressure, stress, hydraulic and frictional parameters vary and interact between them within the numerical experiments. During the injection, the pressure and fluid flow are related to the hydraulic aperture through the modified cubic law (Witherspoon et al., 1980). The hydraulic aperture only varies with the effective normal stress, if a dilation angle is not considered; otherwise, shear-induced dilation also contributes to increase fault permeability and hydraulic diffusivity (Supplementary, Text S1). The fault is reactivated when the Mohr-Coulomb failure criterion is reached, either by a decrease of the effective normal stress or by an increase of the shear stress (Jaeger et al., 2009). Then, slip begins and the slip velocity may increase. During the slip periods, we consider that the friction coefficient decreases with slip, assuming a linear slip-weakening friction law (Ida, 1972). At each time step, in addition to slip, aperture, stress and pressure, the slip velocity is also measured to detect the occurrence of seismic events. Observed failures are considered seismic if a slip velocity threshold is reached (Cochard and Madariaga, 1994). Here, we consider a typical threshold of $1 \mathrm{~mm} / \mathrm{s}$. Within a seismic time window, subsequent seismic failures on neighboring patches are then gathered to form individual seismic events, whose magnitude is estimated from the size of the failure area and the slip amplitude together with the rock shear modulus. As the nucleation length of such seismic events is much lower than the grid cells, this inherently discrete rupture approach does not allow us to compute the details of the nucleation phase of each seismic slip (Wynants-Morel et al., 2020), but it leads to model swarm of micro-seismic events that span several order of magnitude differences (-1.6 to 0.7$)$. For more details on the hydromechanical and seismological assumptions made in the modelling used in this study, we refer the readers to Wynants-Morel et al. (2020).

We numerically test the response of a single permeable fault to a fluid injection, with the same set-up as Wynants-Morel et al. $(2020,2021)$. Injection occurred at the center of a $70^{\circ}$-dipping, $106 \times 100 \mathrm{~m}$, planar fault (i.e., no roughness). The fault is embedded in an impermeable and elastic medium, and it has stiff elastic properties and slip-weakening frictional parameters for shear slip (Supplementary, Fig. S1). The hydromechanical and frictional properties are initially uniform over the fault (Supplementary, Tab. S1). The 
applied stress state corresponds to faults at typical reservoirs depth (i.e., $3 \mathrm{~km}$ depth), with principal stresses of $\sigma_{z z}=81 \mathrm{MPa}, \sigma_{x x}=\sigma_{y y}=70 \mathrm{MPa}$. We quantify the fault criticality, which is the initial closeness to failure of the fault, by the Shear Capacity Utilization (SCU) (Buijze et al., 2019). It is defined as the ratio between initial shear stress $\left(\tau_{0}\right)$ and initial strength on the fault $\left(\tau_{f_{0}}\right)$, before the start of the injection:

$$
S C U=\frac{\tau_{0}}{\tau_{f_{0}}}=\frac{\tau_{0}}{\mu_{S}\left(\sigma_{n_{0}}-P_{0}\right)}
$$

where $\mu_{\mathrm{s}}$ is the initial friction coefficient of the fault, and $\sigma_{\mathrm{n} 0}$ and $\mathrm{P}_{0}$ are the initial normal stress and fluid pressure, respectively. In order to vary the fault criticality without modifying the normal stress, we arbitrarily add a deviatoric stress component $\sigma_{x y}$. In order to reach failure, with a pressure significantly higher than the hydrostatic one, $\sigma_{x y}$ ranges between 13.5 and $18.5 \mathrm{MPa}$, which leads to SCU values varying from 53 to $71 \%$.

We assume an initial aperture of the fault ranging between $80 \mu \mathrm{m}$ and $260 \mu \mathrm{m}$. Using a cubic law to model fluid flow in a smooth fault (Witherspoon et al., 1980), this high value of aperture is equivalent to a permeability comprised between $5.3 \times 10^{-10}$ and $5.6 \times 10^{-9} \mathrm{~m}^{2}$, respectively. Therefore, we are here intentionally testing a highly conductive fault, at the higher end of the permeability values observed for faults in the field (Scibek, 2020). Such a high permeability is representative of a mature fault zone with an intensively fracture damage zone, commonly observed in the first kilometers of the crust, and consistently, with in-situ tests conducted in boreholes across well-developed fault zones (e.g., Jeanne et al., 2012). In the 3DEC hydromechanical modeling, a modified cubic law is assumed to model fluid flow in a deformable fault (Witherspoon et al., 1980). The range of tested aperture $(80$ to $260 \mu \mathrm{m})$ leads to a transmissivity between $\mathrm{T}=$ $4.185 \times 10^{-7}$ and $1.43 \times 10^{-5} \mathrm{~m}^{2} / \mathrm{s}$ and a storativity of about $2.3 \times 10^{-5}$. Therefore, initial diffusivities range from 0.018 to $0.616 \mathrm{~m}^{2} / \mathrm{s}$ (see Supplementary Text S1 for details on the hydraulic properties computation). These values of diffusivity are within the conventional range $\left(0.01\right.$ and $\left.10 \mathrm{~m}^{2} / \mathrm{s}\right)$ estimated from the analysis of seismic migration (e.g., Parotidis et al., 2003; Shapiro et al., 2002; Talwani et al., 2007) and measured in-situ with high-pressure injection testing on fractures (Rutqvist et al., 1998).

To simulate the injection, the applied flowrate is controlled, as it linearly increases during the first hundred seconds before being kept constant at $0.09 \mathrm{~m}^{3} / \mathrm{s}$. It corresponds to a high-rate injection that produces a rapid and intense pressurization of the fault. For sake of comparison between the different numerical experiments, the simulations are stopped when the rupture reached a fixed distance from injection point, corresponding to $38 \mathrm{~m}$ and $76 \%$ of the length of the fault. Such rupture size is reached in a few hundreds of seconds.

\subsection{Method for the seismic front analysis}

We run different simulations by varying the fault criticality and the initial hydraulic diffusivity of the fault (Supplementary, Tab. S1). The latter is obtained by modifying the initial hydraulic aperture, and hence the initial permeability (Supplementary, Text S1). Every simulation leads to a synthetic earthquake catalog, which contains the location, timing and magnitude of the seismic events. We then use these catalogs to characterize and study the seismic front, and hence the aseismic slip front, in order to correlate it to fault properties. We could here compute directly the aseismic front from the synthetic time-lapse deformation, but we prefer to adopt a process that we could then apply on real data. For tectonic earthquake swarms, the initial time of the sequence is poorly constrained and the assumption of a point source injection is usually spurious. As usually done, we therefore take as reference the time and median location of the first events. As a few events are always outside the main cloud because of either mislocation or background seismicity, the envelope of the 
seismic events is not straightforward to determine. We define time-sliding windows with length of $10 \%$ and $4 \%$ of the total duration of the seismic swarm with $90 \%$ and $80 \%$ overlap for the synthetic and observed datasets, respectively. Within each of the windows, we measure the distance that encompasses $90 \%$ and 85 $\%$ of the seismicity on both types of catalogs, respectively (Goebel and Brodsky, 2018). These parameters, used to identify the seismic front, differ between natural and synthetic datasets as the latter contain much less events but without any uncertainty on their location. Finally, we smooth the distance-time front by reinterpolating it with a regular time step (see Supplementary, Fig. S2).

We then characterize the seismic front in a distance-time diagram with different metrics. The mean velocity $V_{\text {mean }}$ is obtained by fitting a linear model to the front and gives a qualitative, simple idea on the migration behavior. To gather best-fitting parameters for the diffusive and linear models from the same measurements, the shape of the front can be described by an equation of the form:

$$
R(t)=\alpha t^{\beta}
$$

The $\beta$-exponent describes the shape of the curve. The coefficient $\alpha$ is exactly equal to $\sqrt{4 \pi D}$ or to $V_{\text {mean }}$, for a diffusive law $(\beta=0.5$ ) or a linear model $(\beta=1)$, respectively. Else, $\alpha$ can be seen as a normalizing constant, of dimension $t^{-\beta}$. The estimation of $\alpha$ and $\beta$ is performed by a linear regression in the $\log (\mathrm{R})-\log (\mathrm{t}) \operatorname{domain}$. We also fit such a law on the first half $\left(\beta_{\text {beg }}\right)$ or the second half $\left(\beta_{\text {end }}\right)$ of the front, to explore how the front evolves with time. Note that fitting in a log-log scale inherently gives more weight to the points at shorter time. Therefore, we always find that $\beta_{\text {beg }}$ is very close to $\beta$, and we then only use $\beta$ and $\beta_{\text {end }}$. Finally, to compare how the seismicity and the fluid pressure move away from the injection in synthetic data, we apply the same approach on the pressure front. It is defined as the radial distance for which the pressure perturbation arbitrarily reaches $1 \%$ of the initial, hydrostatic pressure. We then measure the shape of this front using eq.3, leading to the measure of the exponent $\beta_{P}$.

\section{Results}

As shown by Wynants-Morel et al. (2020), the fault deformation is dominantly aseismic in response to the fluid injection. Indeed, even for the most critical fault (SCU = 71\%), the seismic-to-aseismic moment ratio only reaches $3.2 \%$. While the fluid pressure shows a nearly radial diffusion, the aseismic slip occurs on an elongated ellipse, with the longer axes in the direction of the major stress component (Fig. 1a). For high criticality stress cases, this elliptical shape of deformation outpaces the pressure front, such as in Fig. 1. Therefore, the rupture is not triggered anymore by the fluid overpressure, but by the stress concentrations at the tips of the expanding aseismic deformation (Wynants-Morel et al., 2020). In faults with a low SCU, the slip does not break out from the fluid pressurized area. However, the seismicity still follows the aseismic slip, as it is also triggered by the stress concentration at the slip edges. Therefore, in a distance-time plot, the seismicity front and the aseismic slip front are the same (Fig. 1b). Ahead or behind these fronts, the fluid pressure front displays a different shape. 

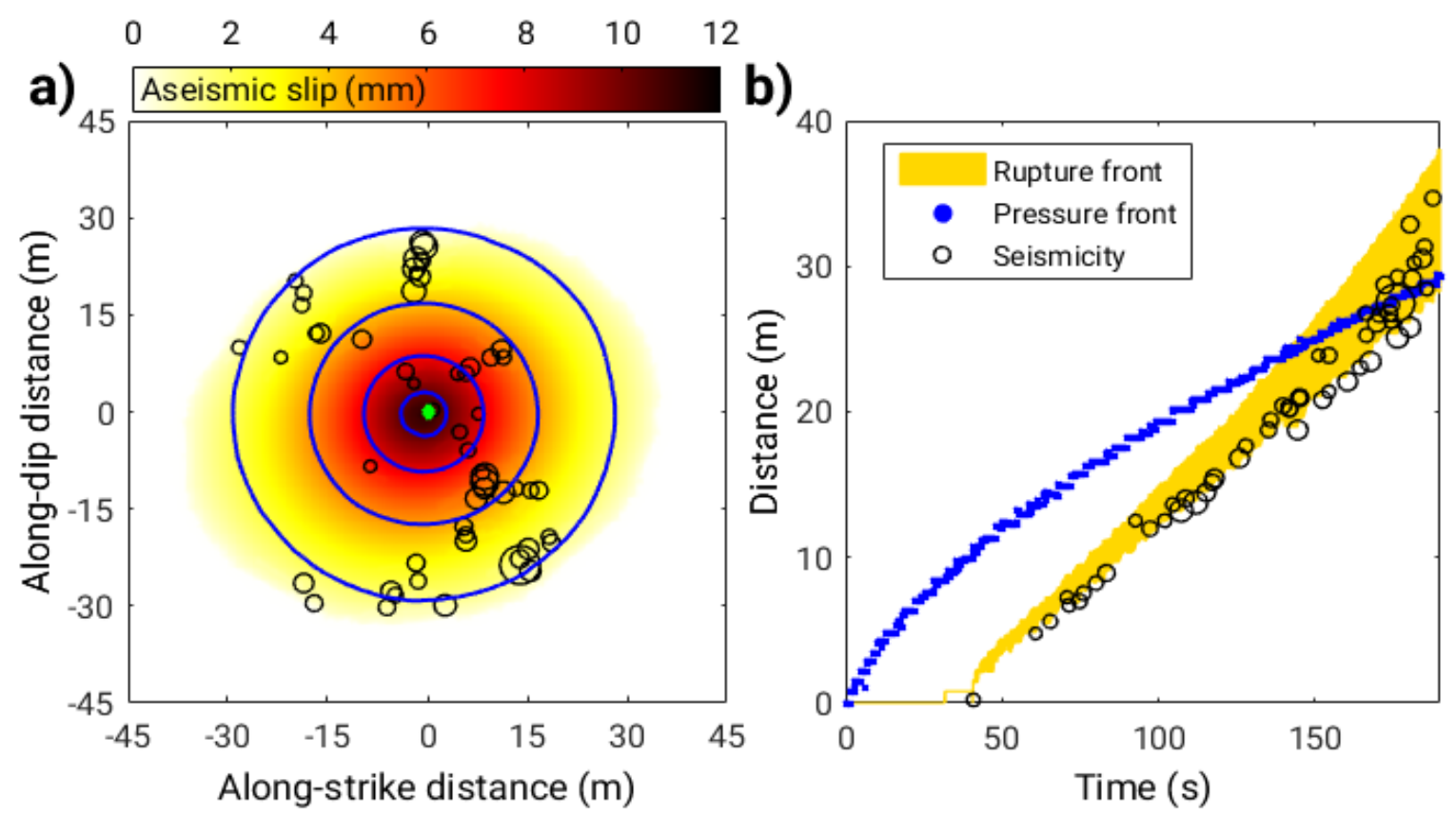

Figure 1. Numerical response of a slip-weakening, permeable fault to a fluid injection. The fault is in a rather high critical state (SCU =68\%). (a) Plan view of the fault, with the injection location shown with a light green diamond symbol. Colors display the amplitude of the aseismic slip, while seismic events are represented with black circles sized by their magnitudes (from -1.5 to -0.8). The blue circles show fluid over-pressure contours of $1 \%, 10 \%, 33 \%$ and $67 \%$ of the initial hydrostatic pressure (30 MPa at the injection point). (b) Distance-time plot, with the pressure front (blue) defined as $1 \%$ over-pressure and the seismic events (black dots). The elliptical shape of the aseismic rupture in (a) leads to the yellow area in the distance-time plot. The distance is the distance relative to the injection point.

\subsection{Migration of the fluid pressure front}

Before investigating the migration of the seismicity, we first focus on the fluid pressure diffusion. At first glance, the shape of the pressure front seems consistent with a diffusion behavior (Fig. 2a and 3a). However, the migration of the fluid pressure cannot be exactly reproduced by a diffusion law (eq. 1), because (1) flowrate and pressure are not constant at the injection and (2) the hydromechanical coupling between the hydraulic aperture and the fault deformation produces diffusivity changes with time. Considering the dilatancy effect with shear slip, that is an additional hydromechanical coupling to the effective stress, amplifies even more the discrepancy between the pressure front and a theoretical diffusion law, as pressure fronts accelerate with time (Supplementary, Fig. S3). Despite this coupling effect, the fluid pressure migration is not sensitive to the fault criticality, as the pressure fronts share the exact same shape whatever the SCU (Fig. 2a). However, as the injection time differs among tests, the final position of the pressure front curve is not the same among the different tests. The longest tests are obtained with the smallest criticality, and show pressure migration with an exponent very close to 0.5 and a diffusivity close to the theoretical one ( $D=0.28 \mathrm{~m}^{2} / \mathrm{s}$ ). For higher criticality faults, the hydraulic response departs from a diffusive behavior, with an exponent $\beta_{P}$ up to 0.77 . Finally, and consistently with a diffusive law (eq. 1), the pressure front strongly depends on the initial hydraulic diffusivity, and hence on the permeability. However, the pressure front departs from a diffusive law and the apparent diffusivity is observed much larger than the theoretical one (Fig. 3a). 

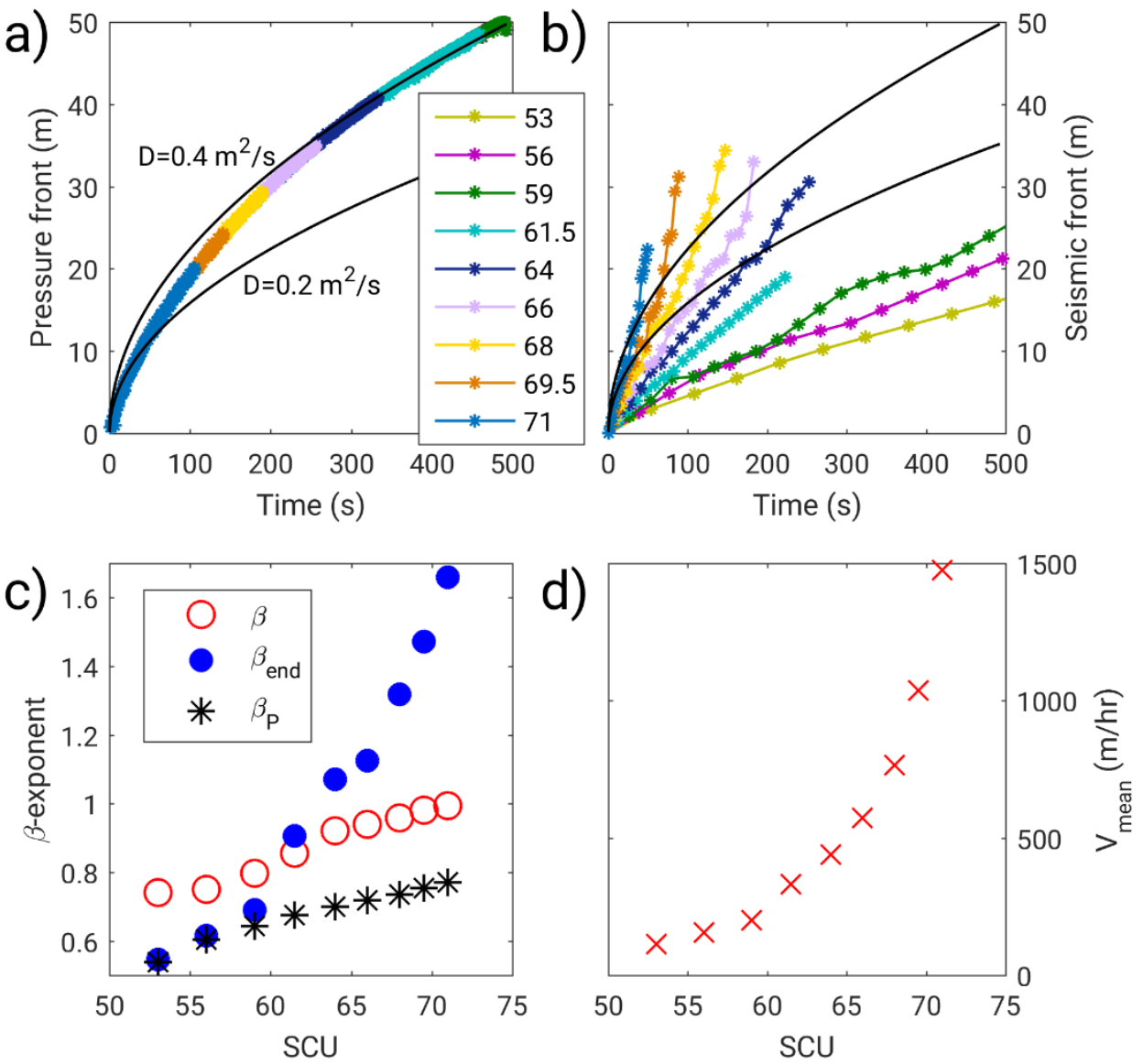

Figure 2. Relation between pressure front, seismic migration and fault criticality (SCU). Distance-time plots for (a) the overpressure front (defined as $1 \%$ of the initial hydrostatic pressure) and (b) the reconstructed seismic front, which is also the aseismic front. In both (a) and (b), results are colored according to the fault criticality (SCU in \%). For sake of reference, the black lines show the theoretical curves (eq. 1) for hydraulic diffusivity of $D=0.2$ and $0.4 \mathrm{~m}^{2} / \mathrm{s}$. (c) Best fitting exponent for the pressure front $\left(\beta_{P}\right)$, for the seismic front and its second half ( $\beta$ and $\beta_{\text {end }}$, respectively), with respect to the SCU (\%). (d) Mean seismic migration velocity $\left(V_{\text {mean }}\right)$ with respect to the SCU (\%).

\subsection{Migration of the seismic front}

Contrary to the pressure front that generally looks broadly compatible with a diffusive law (Fig. 2a), the shape of the seismic fronts, or equivalently to the aseismic rupture front, behaves differently. Indeed, the seismic front may be either slowing down, evolving at a constant rate or accelerating with time, depending on the fault criticality (Fig. 2b). For low-criticality stressed faults, the seismicity is contained within the fluid pressurized area, while the seismic front outpaces the pressure front for faults with a high-critical stress state. The mean velocity of the seismic fronts strongly varies from $\sim 100 \mathrm{~m} / \mathrm{hr}$ to $\sim 1500 \mathrm{~m} / \mathrm{hr}$ with increasing criticality. Note that these values are one order of magnitude higher than typical values observed for injectioninduced or natural swarms, because of the high initial fault aperture and the high pressurization rate used in 
our modellings. The seismic front does not follow a diffusion law, at least for the faults with the highest SCU. The global shape of this front is characterized by a $\beta$-exponent that varies from 0.74 to 1 with increasing SCU. This variation with the SCU is similar for the pressure and the seismicity, except that the seismic front exponent is consistently $\sim 0.2$ higher $\left(\beta=\beta_{p}+0.2\right)$. As for the pressure front, the variations of $\beta$ with the SCU may be related to the different durations of the synthetic tests. However, the migrating behavior is very different when considering only the second half of the seismic front. The exponent $\beta_{\text {end }}$ is found here to vary from 0.5 , i.e. similarly to a pressure diffusion, to 1.5 with increasing fault criticality. It means that the seismic front migration slows down with time when the fault is not critically stressed, and may strongly accelerate for critically stressed faults. To summarize, the initial stage of the seismic front migration behaves similarly as the pressure front. Later on, the seismic front evolves depending on the stress state, with the accelerating migration with increasing fault criticality. In the high-critically stressed cases, the rupture is not pressurecontrolled and runs away from the pressurized zone with an accelerating velocity.

To confirm this statement, we also analyze the evolution of the seismic front with the fault hydraulic properties. First, while the pressure front shape strongly depends on the fault dilation, the seismic front stays nearly unchanged for faults with different dilation angles (Supplementary, Fig. S3). The mean velocity and the $\beta$-exponent only slightly increase from 760 and $860 \mathrm{~m} / \mathrm{hr}$, and from 0.95 to 1.05 , respectively, when dilation angle changes from 0 to $8^{\circ}$. Similarly, modifications in initial hydraulic diffusivity lead to sharp changes in the migration velocity of both the fluid pressure and the seismic (and equivalently the aseismic deformation) fronts. However, it does not modify the shape of the migrating seismic front, as both $\beta$ and $\beta_{\text {end }}$ stay unchanged with varying diffusivity or permeability (Fig. 3). Therefore, hydraulic properties and their variations with hydromechanical coupling strongly affect the shape of the pressure front, but not of the seismic front. In summary, the shape of the seismic front does not depend on fault hydraulic properties, but on the fault criticality. On the contrary, the seismic migration velocity depends on both the fault criticality and the hydraulic properties. Therefore, interpreting the shape of the migration front may bring key insights on the mechanical properties and stability of the faults, without ambiguity with fault hydraulic properties. 
Author version

Published in Journal of Geophysical Research - Solid Earth,
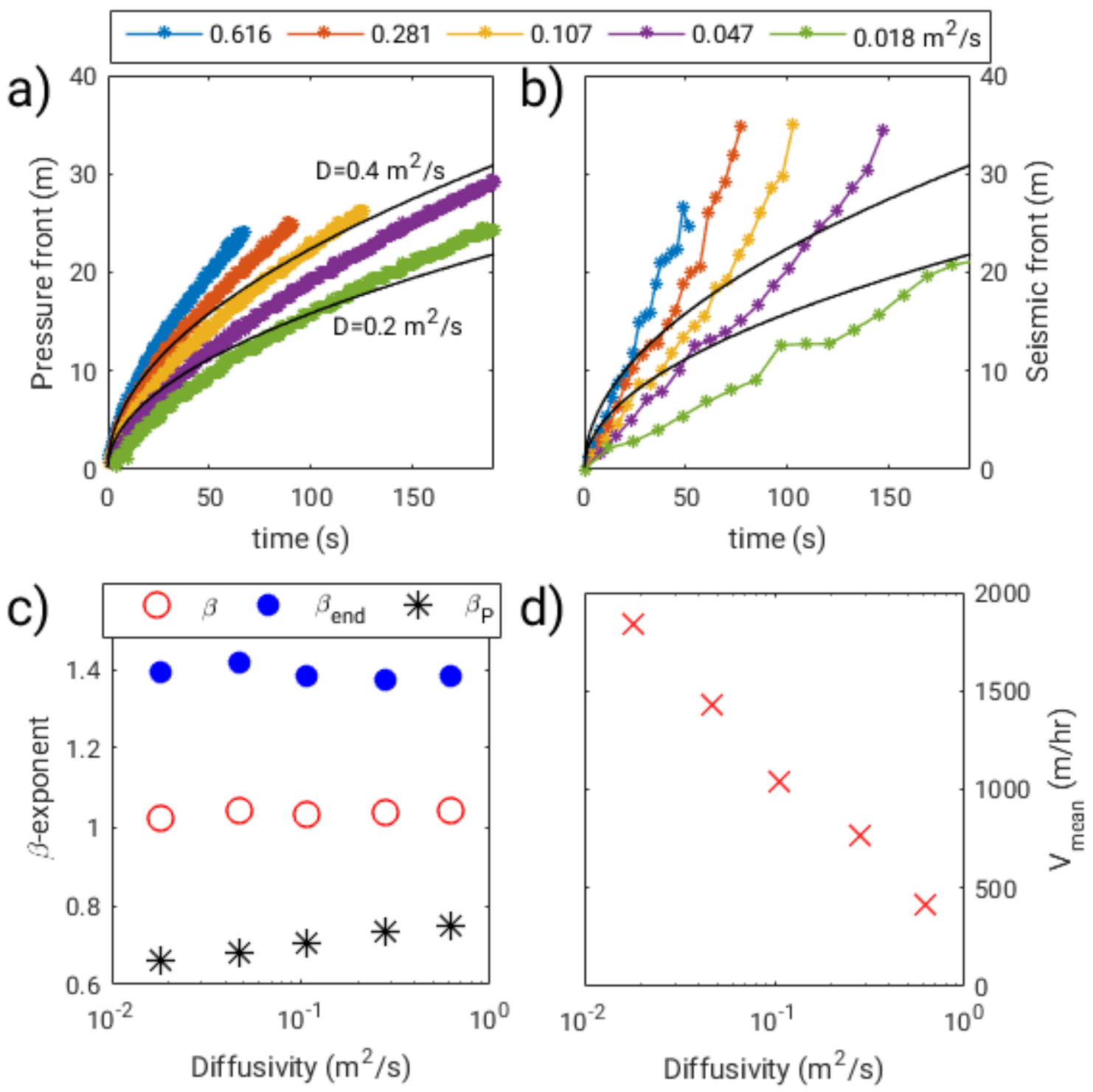

Figure 3. Relation between pressure front, seismic migration and initial hydraulic diffusivity $\left(\mathrm{m}^{2} / \mathrm{s}\right)$. The latter is modified by changing the initial fault aperture (from 80 to $260 \mu \mathrm{m}$ ) and thus the permeability. Distance-time plots for (a) the overpressure front (defined as $1 \%$ of the initial hydrostatic pressure) and (b) the reconstructed seismic front, which is also the aseismic front. In both (a) and (b), results are colored according to the diffusivity. For sake of reference, the black lines show the theoretical curves (eq. 1) for a diffusivity of $D=0.2$ and $0.4 \mathrm{~m}^{2} / \mathrm{s}$. (c) Exponent $\beta$ measured on the pressure front $\left(\beta_{P}\right)$, on the beginning and on the second half of the seismic front ( $\beta$ and $\beta_{\text {end }}$, respectively), with respect to the diffusivity. (d) Mean seismic migration velocity $\left(V_{\text {mean }}\right)$ with respect to the diffusivity. 
Author version

Published in Journal of Geophysical Research - Solid Earth,

Doi: $10.1029 / 2021 J B 022767$

\subsection{Comparison with the seismic migration in injection-induced swarms}

We then aim at extrapolating these numerical results to field observations of induced seismicity by fluid injections in subsurface reservoirs. In order to quantify the mechanical state of a fault available for both datasets, we use the seismogenic index $\Sigma$ defined by Shapiro et al. (2010) as:

$$
\Sigma=\log N_{M>M_{c}}-\log (V)+b M_{c}
$$

This parameter describes the seismogenic state of a reservoir, as it highlights the difference between (1) the earthquake productivity as expressed in the Gutenberg-Richter law ( $N_{M}>M_{c}$ being the number of events above a magnitude $M_{c}$, and $b$ the Gutenberg-Richter exponent) and (2) the injected fluid volume $V$, which controls the induced deformation (McGarr and Barbour, 2018). Therefore, a largely negative $\Sigma$ value might indicate that the deformation is mainly aseismic, while a positive value suggests a dominantly seismic response. The seismogenic index is an empirical, but measurable, quantification of the seismic-to-aseismic ratio. As shown by Wynants-Morel et al. (2021), this ratio mainly depends on the fault criticality toward the stress state, among other parameters. Therefore, the seismogenic index is also likely depending on the criticality of the stress state of the faults. This is confirmed by the linear relationships observed between the SCU and $\Sigma$ on synthetic catalogs (Fig. 4). We can therefore repeat with the seismogenic index the statements made using the SCU, and we observe that the exponent $\beta$ that characterizes the seismic front varies similarly with either the SCU or the seismogenic index (Fig. 4b).

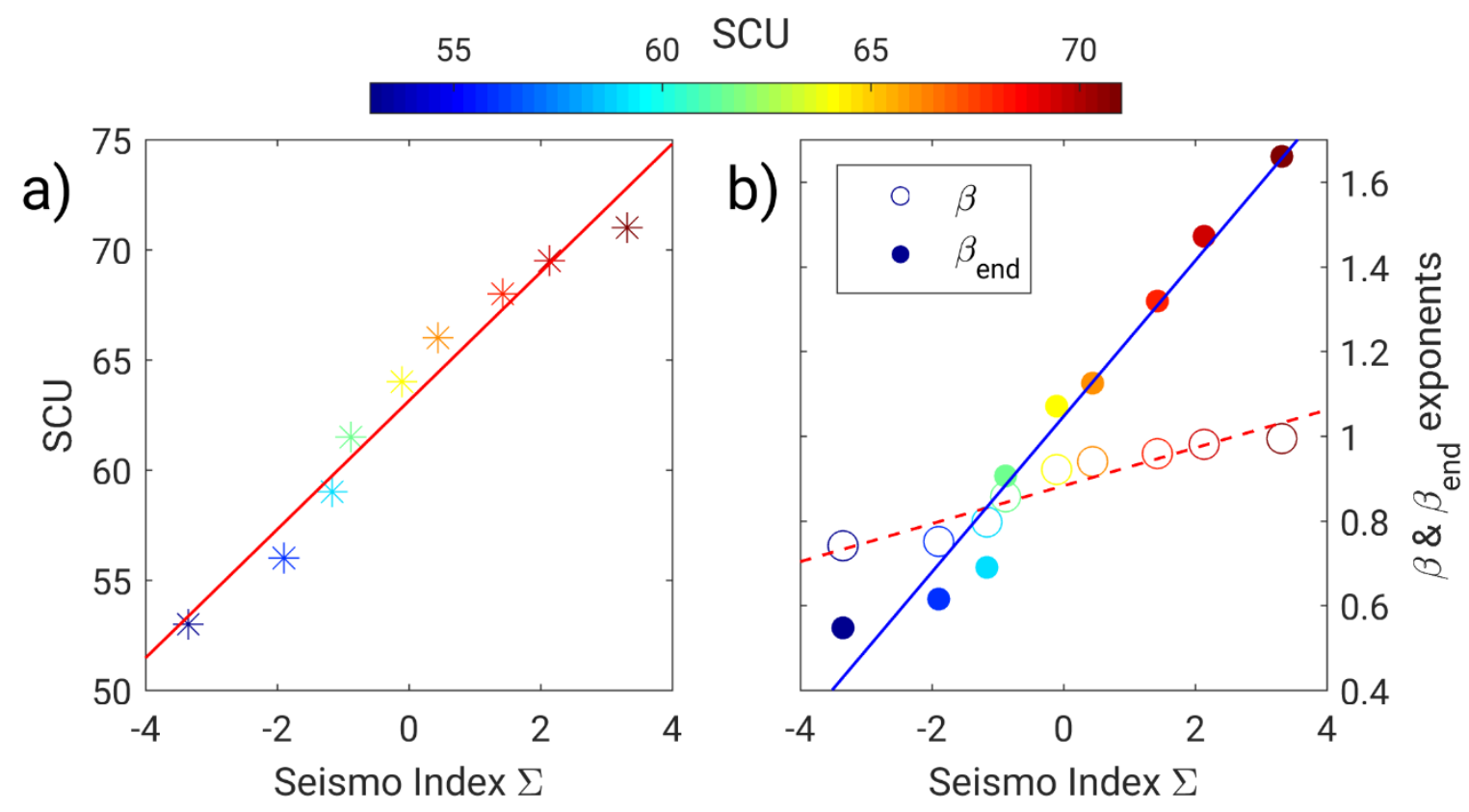

Figure 4. (a) Fault criticality (SCU in \%) versus seismogenic index ( $\Sigma$ ); (b) Exponents $\beta$ (empty symbols) and $\beta_{\text {end }}$ (filled symbols) measured on the distance-time plots versus seismogenic index. All parameters are estimated from synthetic seismic catalogs. In both panels, color highlights the SCU values.

We then consider 7 seismic swarms induced by hydraulic injections. They were all recorded on enhanced geothermal systems to share a homogenous environment. In details, 5 injection tests were performed in Soultz-sous-Forêts, France, for experimental purposes in 1993 (Bourouis and Bernard, 2007; EOST \& GEIE EMC, 2017), 1995 (Gerard et al., 1997; GEIE EMC \& EOST, 2019a), 1996 (Gerard et al., 1997; GEIE EMC \& EOST, 2019b), 2000 (Cuenot et al., 2008; GEIE EMC \& EOST, 2018), 2003 (Calò and Dorbath, 2013; EOST \& GEIE EMC, 
2018). The remaining 2 datasets are associated with injections in Cooper Basin, Australia, 2012, (Baisch et al., 2015; IS EPOS, 2020) and Basel, Switzerland, 2006 (Deichmann and Giardini, 2009; Herrmann et al., 2019). In all cases, fluid stimulations were conducted by increasing flow-rate step-by-step or using a nearly constant flowrate (Audigane et al., 2002; Charléty et al., 2007; Baisch et al., 2015). While pressure increases for low flowrate, a constant steady state is then quickly reached (Audigane et al., 2002). All the injections occurred at similar depth ( 3 to $5 \mathrm{~km}$ depth), in similar geological materials and with comparable fluid volume (between $11,500 \mathrm{~m}^{3}$ in Basel and 34,000 $\mathrm{m}^{3}$ in Cooper Basin). Therefore, in addition to of the hydraulic properties, two main differences among the different cases are likely to be the orientation of the faults toward the stress state and their frictional properties. Both parameters are unknown or imperfectly known, but they both influence the criticality of the faults to slip.

It is worth noting that the shape of the seismic migration is visually different among cases. For example, the distance-time plots in Fig. 5 show that the migration of the seismic front is linear or even accelerating in the Basel case (Fig 5a), while it slows down with time in the case of the 1993 injection in Soultz-sous-Forêts (Fig. 5b). Distance-time plots for the 5 remaining cases also show that the seismic front displays variable shape (Supplementary, Fig. S4). To quantify this difference, we measure the velocity and the shape ( $\beta$-exponent) of the seismic migration front following the same approach as developed for the synthetic data. Figure 6 shows the variation of those migration parameters with the seismogenic index for the different reservoirs. On average, the migration velocity tends to increase with the seismogenic index (Fig. 6b). However, this linear dependency is broken for some injections (i.e., Soultz, 1996), showing that the relation between migration velocity and seismogenic properties is not straightforward, as expected from numerical results. This may be because it depends on several additional parameters, including fault hydraulics (i.e., permeability), that are not directly encompassed in the seismogenic index.

Following the approach applied on synthetic data, the shape of the migration front is measured as the time exponent on either the full $(\beta)$ or only the second half of the sequence $\left(\beta_{\text {end }}\right)$. While the first one $(\beta)$ does not vary much with the seismogenic index, $\beta_{\text {end }}$ shows a clear and linear increase with the seismogenic index (Fig. 6a,c). Indeed, as these exponents are measured in a log-log scale, $\beta$ is very sensitive to the migration at short time. Therefore, as $\beta$ is always close to 0.5 , it indicates that the sequences always started with a migration close to a diffusion. Later on, the migration depends on the seismogenic state of the fault. For low seismogenic index $\Sigma, \beta_{\text {end }}$ is smaller than or very close to $\beta \sim 0.5$ and the migration velocity is slowing down with time. On the contrary, for high $\Sigma$, the migration accelerates, with $\beta_{\text {end }}$ much larger than 0.5 . For example, the shape of the migration strongly evolved with time in Basel injection (Fig. 5a) but not in Soultz 1993 injection (Fig. 5b), while the beginning of both migrating sequences is rather diffusive. The differences between $\beta_{\text {end }}$ and $\beta$, i.e. the difference of the exponents that describe the migration shape at different time stages, is thus directly related to the seismogenic index (Fig. 6c). The higher is the seismogenic index, the larger is $\beta_{\text {end }}$ and the difference between $\beta_{\text {end }}$ and $\beta$, i.e., the more the migration is accelerating. Finally, the dependency between the exponent $\beta_{\text {end }}$ and the seismogenic index $\Sigma$ is found exactly similar for synthetic and numerical catalogs with $\beta_{\text {end }} \approx 0.2 \Sigma+1$. This confirms that the shape of the migration front at later stage is related to the seismogenic index, and by extrapolation from the numerical modelling, to the critical stress state of the fault. Therefore, it may be used as a probe for the seismogenic state of a fault, i.e., to describe the ability of a fault to respond seismically to a given fluid perturbation. 
Author version

Published in Journal of Geophysical Research - Solid Earth,

Doi: 10.1029/2021JB022767
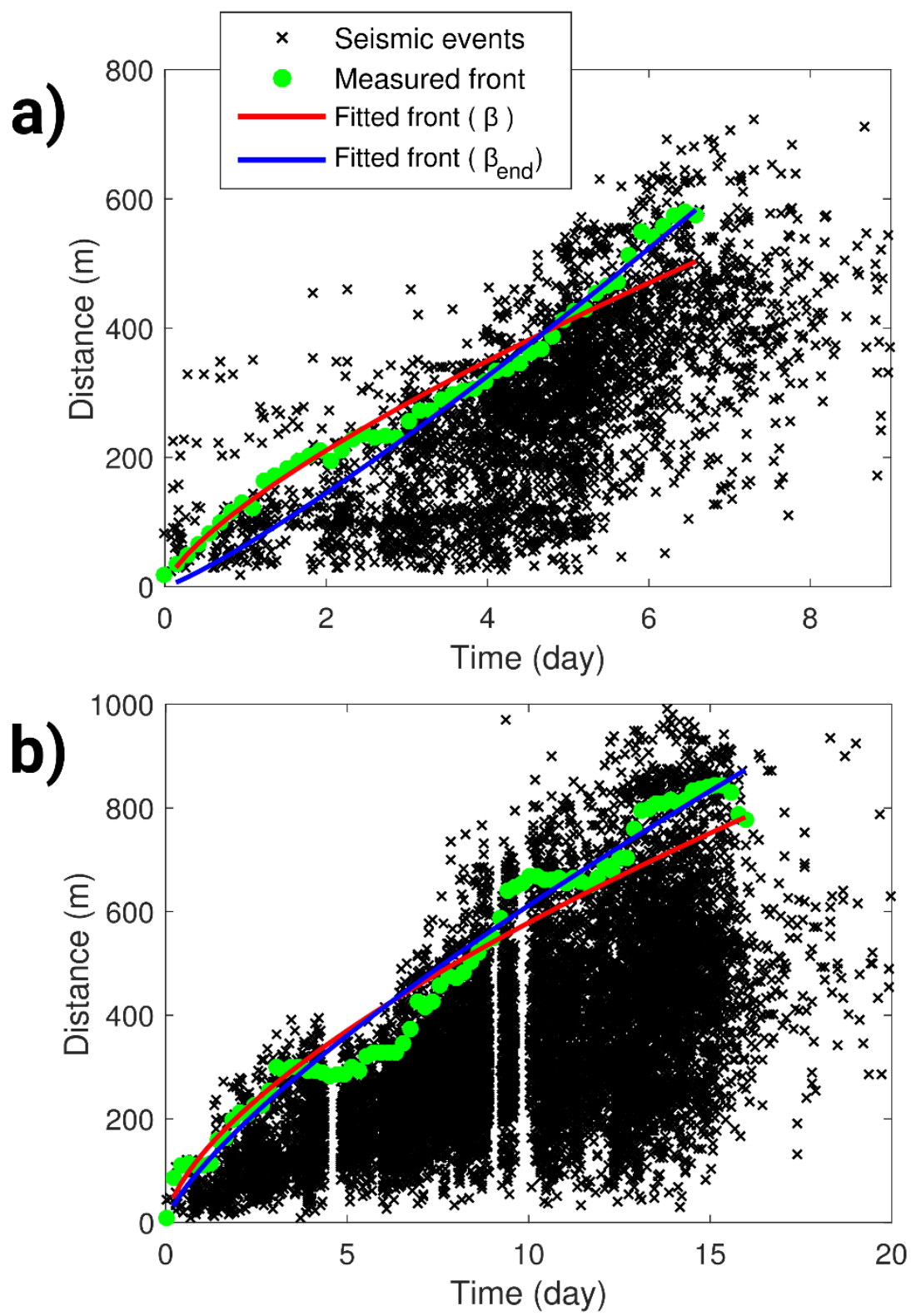

Figure 5. Seismic migration, displayed as distance-time plot, observed in the geothermal fields of (a) Basel, Switzerland (Herrmann et al., 2019), and (b) Soultz-sous-Forêts, France, in 1993 (Bourouis and Bernard, 2007). In both cases, the green dots show the reconstructed seismic front. The red and blue lines are the fits of the seismic front in the logarithmic domain, using the full ( $\beta$-exponent) or only the second half ( $\left.\beta_{\text {end }}-e x p o n e n t\right)$ of the sequence, respectively. See also Supplementary Fig. S4 for the remaining 5 studied cases. Note that the strips at constant time in the seismicity in Fig. $5 b$ are due to gaps in the data. 


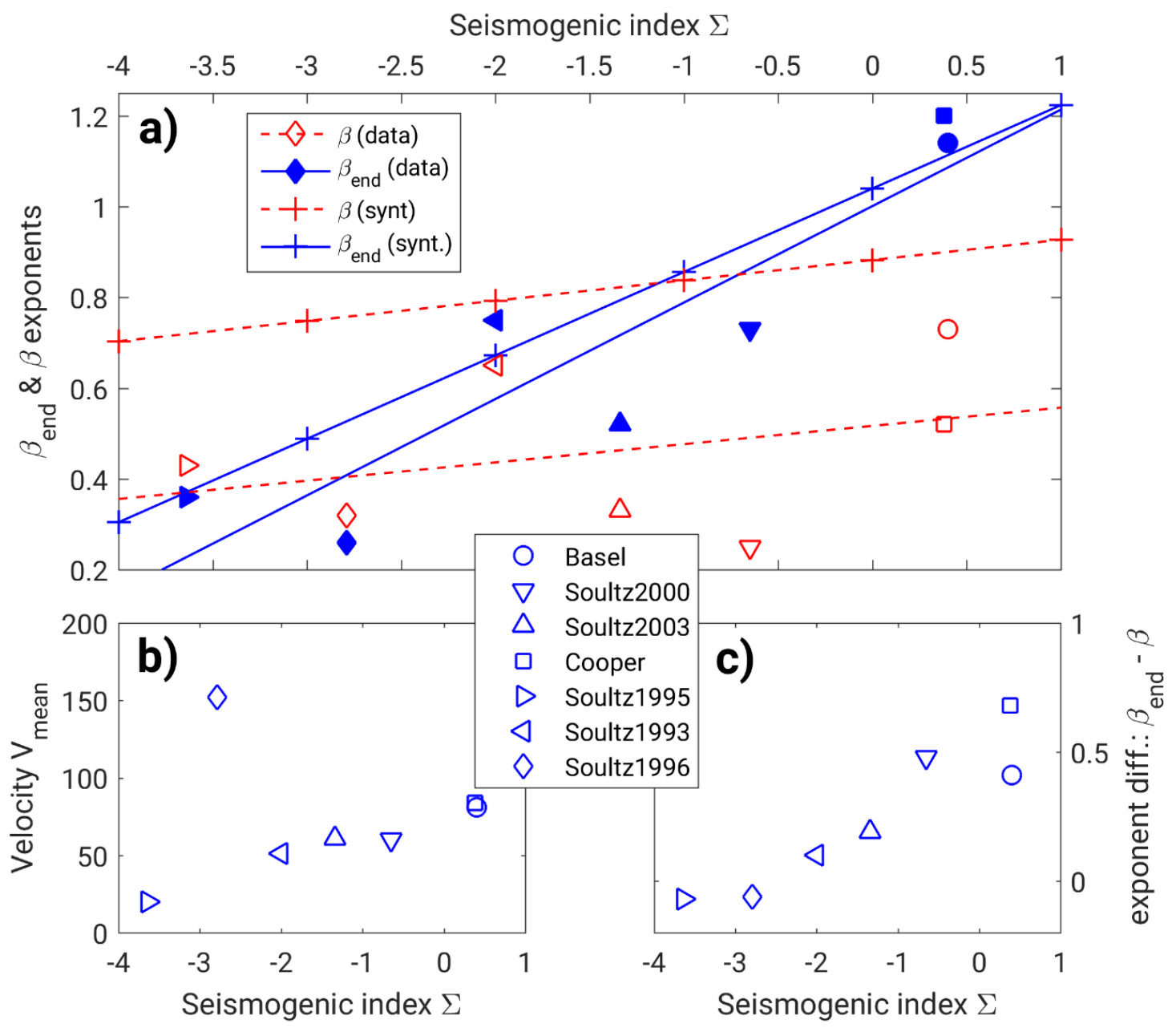

Figure 6. Migration properties versus seismogenic index $\Sigma$ for seven injection swarms. (a) Exponents $\beta$ (red, empty symbols) and $\beta_{\mathrm{end}}$ (blue, filled symbols) measured on the full seismic sequence or on the second half of the distance-time relations versus seismogenic index. The dashed red and plain blue lines show the linear regression on the exponents $\beta$ and $\beta_{\text {end }}$ versus $\Sigma$, respectively. Same lines with crosses (" + ") recall the fits obtained on synthetic catalogs (Fig. 4). (b) Mean velocity $V_{\text {mean }}$ versus seismogenic index $\Sigma$. (c) Differences between $\beta_{\text {end }}$ and $\beta$ versus seismogenic index $\Sigma$.

\section{Discussion}

Based on seismo-hydromechanical modellings, and following previous work of Wynants-Morel et al. (2020, 2021), we show in our modelling that the seismic front is definitely not the pressure front, which is consistent with others theoretical and numerical studies (Bhattacharya and Viesca, 2019; Cappa et al., 2019; Dublanchet, 2019; Dublanchet and De Barros, 2021). Our results show that while the fluid pressure follows a diffusive-like pattern when hydromechanical couplings are limited, the seismic fronts show migrating shapes that vary from diffusive-like to strongly accelerating. Moreover, the seismic front can be ahead or behind the pressure front. In both cases, earthquakes are triggered by the stress concentration at the tip of the aseismic slip that is induced by the fluid pressure increase. Therefore, the seismic migration is not controlled by the fluid diffusion, as previously proposed (e.g., Shapiro et al., 1997), but by the aseismic slip propagation and the associated 
stress perturbation. The main consequence is that the seismic migration cannot be directly interpreted into hydraulic properties, but can be a probe for estimating the seismogenic state of the faults.

Our results also indicate that the velocity of the seismic migration depends on both the hydraulic properties and the seismogenic state of the faults, as it increases with permeability changes and with fault criticality. Therefore, a fast propagation of the seismic front may ambiguously indicate either a high permeability, which is a benefit for fluid circulations in geothermal reservoirs, or a critically stressed fault on which seismicity may evolve toward large events. The shape of the seismic migration in the distance-time plot may represent a less ambiguous alternative to access reservoir and faults properties, even if it appears complex and cannot be reduced to a simple diffusive or linear model (Fig. 7). The seismic migration always seems to start with a diffusive-like pattern, with $\mathrm{R}(\mathrm{t}) \propto \sqrt{\mathrm{t}}$. During this phase, the aseismic fault slip develops within the pressurized area by effective stress decrease, and consequently, with an increase of the earthquake nucleation length in the frictional stability (Fig. 7a). This first stage might be partly controlled by hydraulic properties, to explain the dependency between the migration velocity and the hydraulic diffusivity. However, the diffusivity coefficient might not be exactly the hydraulic coefficient, but might be proportional to it (Bhattacharya and Viesca, 2019). Later on, for faults far from a critical stress state, i.e. with a low seismogenic index, the seismic front still follows a diffusive-like migration with a velocity slowing down with time. In this case, the pressure front stays ahead of the seismic front (Fig. 7c), and the aseismic slip is still driven by the decrease of the effective normal stress. On the contrary, for high-criticality stressed faults, the seismic front leaves the diffusive behavior, and follows a migration that is linear or even accelerating with time. Doing so, the seismic front outpaces the pressure front that stays diffusive. Thus, the aseismic slip that triggers the seismicity runs away from the pressurized area (Fig. 6b). It becomes self-sustained, as the stress concentration at its tips is large enough to propagate the failure without any additional reduction of the effective normal stress by pressure increase.

In all cases, the seismic front might be generically expressed as the addition of two terms. The first term describes the propagation where the aseismic front is driven by effective normal stress drop, either at the start of the sequence, or for low-criticality stressed faults. Following, Bhattacharya and Viesca (2019), this term could be written as $R(t)=\lambda \sqrt{4 \pi D t}$, where $D$ is the hydraulic diffusivity, and $\lambda$ is a coefficient that depends on the fault criticality. The second term should describe the accelerating migration when the aseismic slip propagation becomes self-sustained. This term might therefore be a power-law, such as $R \propto t^{\beta_{\text {end }}}$, with $\beta_{\text {end }}$ larger than $1 / 2$ for critical faults. Empirically, a generic equation to describe the migration can be (Fig. 6):

$$
r=a_{1} \sqrt{t}+a_{2} t^{\beta_{\text {end }}}
$$

With $a_{1}=\lambda \sqrt{4 \pi D}$ and $a_{2}$, two constants that weight the contribution of each term. For faults far away from a critical state, either $a_{2}$ or $\beta_{\text {end }}$ should be very small, so that the second term can be neglected. Both $\lambda$ and $\beta_{\text {end }}$ depends on the critical state of the faults, but also likely on other strength properties. For example, Wynants-Morel et al. (2021) showed that the static-to-dynamic friction drop has a similar influence on the seismic response as the SCU. 


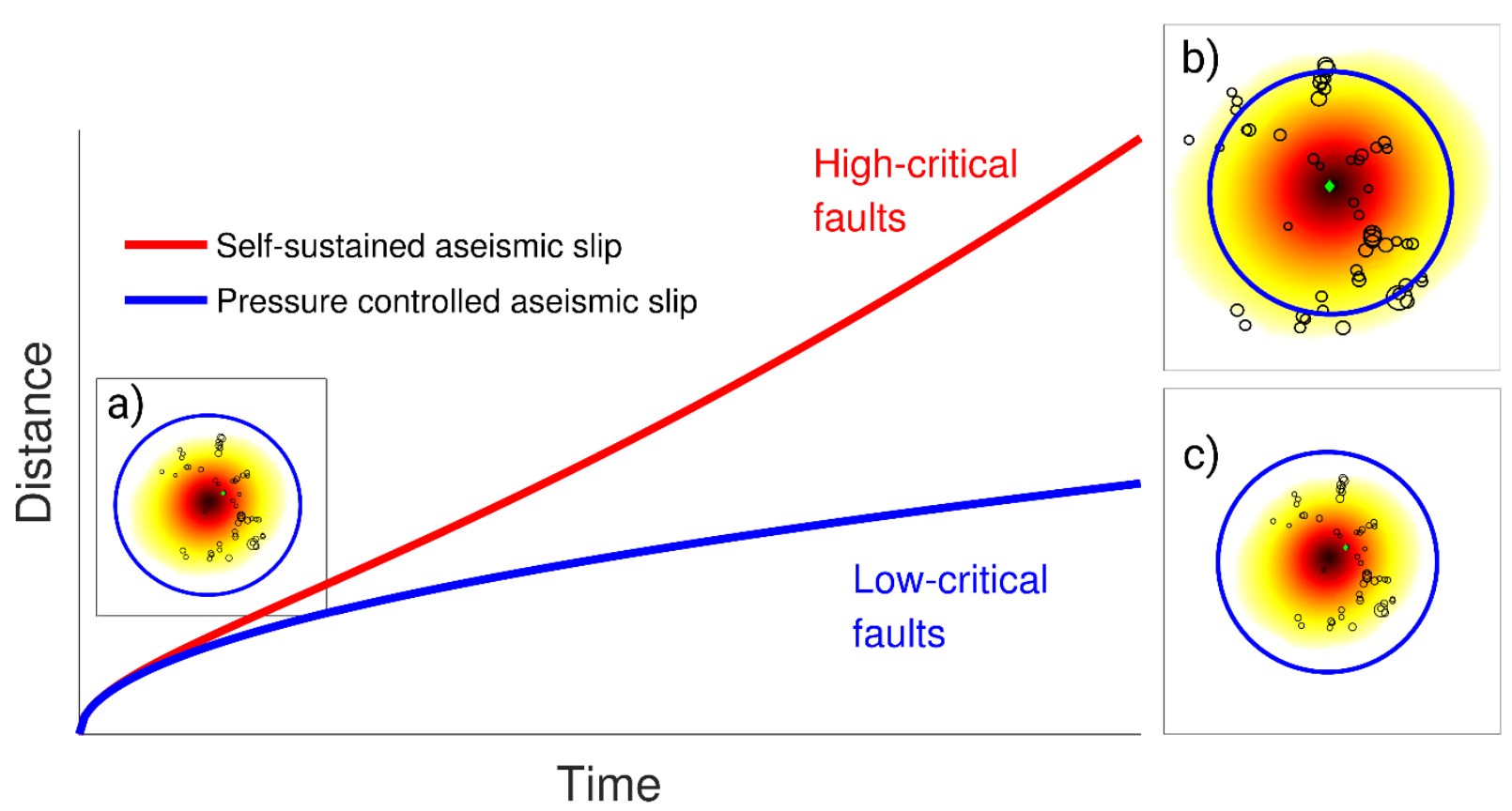

Figure 7. Sketch of the seismic front shape, in a distance-time plot, for a low-criticality stressed fault (blue line) and a high-criticality stressed fault (red line). Both lines are computed using eq. 5 . The insets show the position of the aseismic slip (colors), and hence of the seismicity (black dots) compared to the fluid pressure front (blue line). The swarm sequence always begins as in (a), and then evolve toward (b) for a high criticality stressed fault, in which the aseismic slip propagation is self-sustained and outpaces the pressurized zone, or toward (c) for a low-criticality stressed fault in which the aseismic slip stays driven by the effective stress decrease and remains within the pressurized zone.

The equation 5 reduces to 3 free parameters. However, the reconstruction of the seismic front is rather difficult and unstable. First, the location of the seismic events should be very precise, and any outliers (mislocated events or neighbor events from the background seismicity) may distort the apparent seismic front. The definition of an origin time and location is also rather subjective. Moreover, such migration analysis assumes steady fluid pressure perturbations, with the pressure that then diffuses within faults that share the same properties. The migration behavior may indeed be strongly modified if the fluid flow encounters faults with different frictional properties or with different orientations toward the stress state. Thus, it will be important to extend the analysis of seismicity in models with multiple faults. The flowrate and pressure at the injection also vary during the injection periods, while all models used here, including poro-elastic diffusion, assume a constant, steady-state injection. How the injection schedule may impact the migration pattern should be also explored in detail. Because of all those uncertainties, fitting the model given in eq. 5 to real data may appear overly optimistic. Nevertheless, it still gives a useful framework that allows qualitative interpretations of seismic swarm migrations. For example, Hatch et al. (2020) observed seismic migrations with very different patterns on three different faults during a small swarm near Virginia City (US). Such differences might be associated with variable fault criticality, and a common process of fluid-induced seismicity through aseismic slip. Finally, we here deal with the global migration of swarms, but recent studies showed that migration behavior might be complex, even on a single fault. For example, episodes of fast migration occur within the 
swarms, and bring additional constraints on the driving processes (De Barros et al., 2020; Dublanchet and De Barros, 2021; Fischer and Hainzl, 2021).

As the injected fluid volume is known for injection-induced seismicity, the seismogenic state of the medium can be inferred by comparing the released seismicity and the injected volume through the seismogenic index (Bentz et al., 2020; McGarr and Barbour, 2018; Van der Elst et al., 2016). On the contrary, for tectonic swarms, the migration of the seismicity is among the rare probes that can give insights on the seismogenic state of the faults, and so, on how the swarm may evolve. Therefore, a precise and detailed monitoring of seismic migration, with near-real time and high-quality detections and locations, may prove useful to follow processes at depth, and eventually to anticipate the swarm evolution. For example, without knowledge of the injected volume, the seismic migrations induced by the injection in Soultz-sous-Forêts in 1993 (Fig. 5a) and in Basel in 2006 (Fig. $5 b)$ suggest different seismogenic behaviors that reflect the fault criticality and could help to anticipate the swarm evolutions. While the magnitude of the earthquakes stays below $M=0.8$ in the first case, the injection was shut-in in Basel after an $\mathrm{M}=2.6$ earthquake was felt by the population and was followed by several events of magnitude close to or above 3 . The similarity between natural and injection-induced seismicity suggests that this approach may be also effective in quantifying the seismogenic state in which natural swarms occur.

\section{Conclusion}

By comparing synthetic and observed seismic catalogs, we show that migration patterns of fluid-induced seismic swarms display complex behaviors that cannot be described by a standard poro-elastic fluid diffusion model. The seismicity is triggered by the stress concentrations at the tips of the aseismic slip that is induced by the fluid pressure increase. Therefore, the seismic migration maps and depends on the fault properties that drive the aseismic slip. At the beginning of the swarm, the migrations of the fluid pressure and of the seismicity are both diffusive, but with different diffusivities. Later on, the seismic front migration depends on the seismogenic state of the faults. For faults with a low criticality stress state, the aseismic slip remains driven by the fluid pressure, leading to a diffusive-type migration. On the contrary, for high criticality stressed faults, the aseismic slip leaves the pressurized area with an accelerating migration. In summary, a seismic front with linear shape or accelerating with time indicates a high criticality-stressed fault, while a front that slows down migrates along faults that are not well oriented to promote slips. Therefore, we show that the shape of the seismic migration is directly related to the seismogenic index, and may unambiguously bring insights on the critical stress state of the faults. The mean migration velocity, commonly used to describe process at depth, depends on both hydraulic and mechanical properties of the faults, highlighting the need to consider fault hydromechanical behavior in fluid-induced earthquake studies. Even if such analysis of earthquake migration may stay qualitative because of the difficulty to precisely measure the seismic front, it gives a qualitative framework that might prove useful to anticipate if the swarm is likely to evolve toward large earthquakes.

\section{Acknowledgments}

Data for the Soultz fluid injections were kindly provided by GEIE Exploitation Minière de la Chaleur and distributed on the CDGP web services (https://cdgp.u-strasbg.fr/). Data for the Cooper Basin injection are available on the EPOS platform (IS EPOS, 2020). The Basel catalog comes from the supplementary materials of Herrmann et al. (2019). We thank the authors, refereed in the text, that derive the seismic catalogs and openly distribute them. We thank the editor R. Abercrombie, the associate editor and two anonymous reviewers for their constructive comments that improve this paper. 


\section{Bibliography}

Agurto-Detzel, H., Font, Y., Charvis, P., Régnier, M., Rietbrock, A., Ambrois, D., Paulatto, M., Alvarado, A., Beck, S., Courboulex, F., De Barros, L., Deschamps, A., Hernandez, M.J., Hernandez, S., Hoskins, M., León-Ríos, S., Lynner, C., Meltzer, A., Mercerat, E.D., Michaud, F., Nocquet, J.M., Rolandone, F., Ruiz, M., Soto-Cordero, L., 2019. Ridge subduction and afterslip control aftershock distribution of the $2016 \mathrm{Mw} 7.8$ Ecuador earthquake. Earth and Planetary Science Letters 520, 63-76. https://doi.org/10.1016/j.epsl.2019.05.029

Audigane, P., Royer, J. J., Kaieda, H., 2002; . Permeability characterization of the Soultz and Ogachi large-scale reservoir using induced microseismicity. Geophysics, 67(1), 204-211.

Baisch, S., Rothert, E., Stang, H., Vörös, R., Koch, C., McMahon, A., 2015. Continued geothermal reservoir stimulation experiments in the Cooper Basin (Australia). Bulletin of the Seismological Society of America, 105(1), $198-209$.

Bentz, S., Kwiatek, G., Martínez-Garzón, P., Bohnhoff, M., Dresen, G., 2020. Seismic Moment Evolution During Hydraulic Stimulations. Geophysical Research Letters 47, e2019GL086185. https://doi.org/10.1029/2019GL086185

Bhattacharya, P., Viesca, R.C., 2019. Fluid-induced aseismic fault slip outpaces pore-fluid migration. Science 364, $464-468$. https://doi.org/10.1126/science.aaw7354

Bourouis, S., Bernard, P., 2007. Evidence for coupled seismic and aseismic fault slip during water injection in the geothermal site of Soultz (France), and implications for seismogenic transients. Geophysical Journal International 169, 723-732.

Buijze, L., Bogert, P.A.J. van den, Wassing, B.B.T., Orlic, B., 2019. Nucleation and Arrest of Dynamic Rupture Induced by Reservoir Depletion. Journal of Geophysical Research: Solid Earth 124, 3620-3645. https://doi.org/10.1029/2018JB016941

Calò, M., Dorbath, C., 2013. Different behaviours of the seismic velocity field at Soultz-sous-Forêts revealed by 4-D seismic tomography: case study of GPK3 and GPK2 injection tests. Geophysical Journal International 194, 1119-1137.

Cappa, F., Scuderi, M.M., Collettini, C., Guglielmi, Y., Avouac, J.-P., 2019. Stabilization of fault slip by fluid injection in the laboratory and in situ. Science Advances 5, eaau4065. https://doi.org/10.1126/sciadv.aau4065

Cauchie, L., Lengliné, O., Schmittbuhl, J., 2020. Seismic asperity size evolution during fluid injection: case study of the 1993 Soultz-sous-Forêts injection. Geophysical Journal International 221, 968-980.

Charléty, J., Cuenot, N., Dorbath, L., Dorbath, C., Haessler, H., Frogneux, M., 2007. Large earthquakes during hydraulic stimulations at the geothermal site of Soultz-sous-Forêts. International Journal of Rock Mechanics and Mining Sciences 44, 1091-1105. https://doi.org/10.1016/j.ijrmms.2007.06.003

Chen, X., Shearer, P.M., Abercrombie, R.E., 2012. Spatial migration of earthquakes within seismic clusters in Southern California: Evidence for fluid diffusion. Journal of Geophysical Research: Solid Earth 117. https://doi.org/10.1029/2011JB008973

Cochard, A., Madariaga, R., 1994. Dynamic faulting under rate-dependent friction. pure and applied geophysics 142, 419445.

Cornet, F.H., 2016. Seismic and aseismic motions generated by fluid injections. Geomechanics for Energy and the Environment 5, 42-54. https://doi.org/10.1016/j.gete.2015.12.003

Cuenot, N., Dorbath, C., Dorbath, L., 2008. Analysis of the microseismicity induced by fluid injections at the EGS site of Soultz-sous-Forêts (Alsace, France): implications for the characterization of the geothermal reservoir properties. Pure and Applied Geophysics 165, 797-828.

Dahm, T., Hainzl, S., Fischer, T., 2010. Bidirectional and unidirectional fracture growth during hydrofracturing: Role of driving stress gradients. Journal of Geophysical Research: Solid Earth 115. https://doi.org/10.1029/2009JB006817

Daniel, G., Prono, E., Renard, F., Thouvenot, F., Hainzl, S., Marsan, D., Helmstetter, A., Traversa, P., Got, J.-L., Jenatton, L., 2011. Changes in effective stress during the 2003-2004 Ubaye seismic swarm, France. Journal of Geophysical Research: Solid Earth 116. 
De Barros, L., Cappa, F., Deschamps, A., Dublanchet, P., 2020. Imbricated Aseismic Slip and Fluid Diffusion Drive a Seismic Swarm in the Corinth Gulf, Greece. Geophysical Research Letters 47, e2020GL087142. https://doi.org/10.1029/2020GL087142

De Barros, L., Guglielmi, Y., Rivet, D., Cappa, F., Duboeuf, L., 2018. Seismicity and fault aseismic deformation caused by fluid injection in decametric in-situ experiments. Comptes Rendus Geoscience, Invited contributions by 20162017 geoscience laureates of the French Academy of Sciences 350, 464-475. https://doi.org/10.1016/j.crte.2018.08.002

Deichmann, N., Giardini, D., 2009. Earthquakes induced by the stimulation of an enhanced geothermal system below Basel (Switzerland). Seismological Research Letters, 80(5), 784-798.

Dublanchet, P., 2019. Fluid driven shear cracks on a strengthening rate-and-state frictional fault. Journal of the Mechanics and Physics of Solids 132, 103672.

Dublanchet, P., De Barros, L., 2021. Dual Seismic Migration Velocities in Seismic Swarms. Geophysical Research Letters 48, e2020GL090025. https://doi.org/10.1029/2020GL090025

Duverger, C., Lambotte, S., Bernard, P., Lyon-Caen, H., Deschamps, A., Nercessian, A., 2018. Dynamics of microseismicity and its relationship with the active structures in the western Corinth Rift (Greece). Geophysical Journal International 215, 196-221.

Ellsworth, W.L., 2013. Injection-induced earthquakes. Science 341, 1225942.

EOST \& GEIE EMC, 2017. Episode: 1993 stimulation Soultz-sous-Forêts [Collection]. EOST - CDGP. https://doi.org/10.25577/SSFS1993

EOST \& GEIE EMC, 2018. Episode: 2003 stimulation Soultz-sous-Forêts [Collection]. EOST - CDGP. https://doi.org/10.25577/SSFS2003

Fischer, T., Hainzl, S., 2021. The Growth of Earthquake Clusters. Front. Earth Sci. 9. https://doi.org/10.3389/feart.2021.638336

GEIE EMC \& EOST, 2019a. Episode: 1995 Stimulation and Hydraulic Tests Soultz-sous-Forêts. EOST-CDGP. https://doi.org/10.25577/SSFS1995

GEIE EMC \& EOST, 2019b. Episode: 1996 Stimulation and Hydraulic Tests Soultz-sous-Forêts. EOST-CDGP. https://doi.org/10.25577/SSFS1996

GEIE EMC \& EOST, 2018. Episode: 2000 stimulation Soultz-sous-Forêts. [Collection]. EOST - CDGP. https://doi.org/10.25577/SSFS2000Gerard, A., Baumgärtner, J., Baria, R., \& Jung, R., 1997. An attempt towards a conceptual model derived from 1993-1996 hydraulic operations at Soultz. In Proc. NEDO Internat. Symp. Sendai, Japan. 2, pp. 329-341

Goebel, T.H.W., Brodsky, E.E., 2018. The spatial footprint of injection wells in a global compilation of induced earthquake sequences. Science 361, 899-904. https://doi.org/10.1126/science.aat5449

Grigoli, F., Cesca, S., Rinaldi, A.P., Manconi, A., López-Comino, J.A., Clinton, J.F., Westaway, R., Cauzzi, C., Dahm, T., Wiemer, S., 2018. The November 2017 Mw 5.5 Pohang earthquake: A possible case of induced seismicity in South Korea. Science 360, 1003-1006. https://doi.org/10.1126/science.aat2010

Gualandi, A., Nichele, C., Serpelloni, E., Chiaraluce, L., Anderlini, L., Latorre, D., Belardinelli, M.E., Avouac, J.-P., 2017. Aseismic deformation associated with an earthquake swarm in the northern Apennines (Italy). Geophysical Research Letters 44, 7706-7714. https://doi.org/10.1002/2017GL073687

Guglielmi, Y., Cappa, F., Avouac, J.-P., Henry, P., Elsworth, D., 2015. Seismicity triggered by fluid injection-induced aseismic slip. Science 348, 1224-1226. https://doi.org/10.1126/science.aab0476

Hainzl, S., 2004. Seismicity patterns of earthquake swarms due to fluid intrusion and stress triggering. Geophysical Journal International 159, 1090-1096.

Hatch, R.L., Abercrombie, R.E., Ruhl, C.J., Smith, K.D., 2020. Evidence of Aseismic and Fluid-Driven Processes in a Small Complex Seismic Swarm Near Virginia City, Nevada. Geophysical Research Letters 47, e2019GL085477. https://doi.org/10.1029/2019GL085477 
Herrmann, M., Kraft, T., Tormann, T., Scarabello, L., Wiemer, S., 2019. A Consistent High-Resolution Catalog of Induced Seismicity in Basel Based on Matched Filter Detection and Tailored Post-Processing. Journal of Geophysical Research: Solid Earth 124, 8449-8477. https://doi.org/10.1029/2019JB017468

Ida, Y., 1972. Cohesive force across the tip of a longitudinal-shear crack and Griffith's specific surface energy. Journal of Geophysical Research 77, 3796-3805. https://doi.org/10.1029/JB077i020p03796

IS EPOS, 2020. Episode: COOPER BASIN, https://tcs.ah-epos.eu/\#episode:COOPER_BASIN, doi:10.25171/InstGeoph_PAS_ISEPOS-2020-001

Itasca Consulting Group, 2016. 3DEC, 3-Dimensional Distinct Element Code., Itasca Consulting Group. ed. Minneapolis, MN.

Jaeger, J.C., Cook, N.G., Zimmerman, R., 2009. Fundamentals of rock mechanics. John Wiley \& Sons.

Jeanne, P., Guglielmi, Y., Lamarche, J., Cappa, F., \& Marié, L. (2012). Architectural characteristics and petrophysical properties evolution of a strike-slip fault zone in a fractured porous carbonate reservoir. Journal of Structural Geology, 44, 93-109. https://doi.org/10.1016/j.jsg.2012.08.016

Keranen, K.M., Weingarten, M., 2018. Induced Seismicity. Annual Review of Earth and Planetary Sciences 46, $149-174$. https://doi.org/10.1146/annurev-earth-082517-010054Lohman, R.B., McGuire, J.J., 2007. Earthquake swarms driven by aseismic creep in the Salton Trough, California. Journal of Geophysical Research: Solid Earth 112.

McGarr, A., Barbour, A.J., 2018. Injection-induced moment release can also be aseismic. Geophysical Research Letters 45, 5344-5351.

Nishikawa, T., Ide, S., 2017. Detection of earthquake swarms at subduction zones globally: Insights into tectonic controls on swarm activity. Journal of Geophysical Research: Solid Earth 122, 5325-5343. https://doi.org/10.1002/2017JB014188

Parotidis, M., Rothert, E., Shapiro, S.A., 2003. Pore-pressure diffusion: A possible triggering mechanism for the earthquake swarms 2000 in Vogtland/NW-Bohemia, central Europe. Geophysical Research Letters 30. https://doi.org/10.1029/2003GL018110

Perfettini, H., Frank, W.B., Marsan, D., Bouchon, M., 2018. A model of aftershock migration driven by afterslip. Geophysical Research Letters 45, 2283-2293.

Scibek J. (2020), Multidisciplinary database of permeability of fault zones and surrounding protolith rocks at world-wide sites, Nature Scientific Data, 7:95, https://doi.org/10.1038/s41597-020-0435-5Shapiro, S.A., 2018. Seismogenic Index of Underground Fluid Injections and Productions. Journal of Geophysical Research: Solid Earth 123, 79837997. https://doi.org/10.1029/2018JB015850

Shapiro, S.A., Dinske, C., 2009. Scaling of seismicity induced by nonlinear fluid-rock interaction. Journal of Geophysical Research: Solid Earth 114. https://doi.org/10.1029/2008JB006145

Shapiro, S.A., Dinske, C., Langenbruch, C., Wenzel, F., 2010. Seismogenic index and magnitude probability of earthquakes induced during reservoir fluid stimulations. The Leading Edge 29, 304-309.

Shapiro, S.A., Huenges, E., Borm, G., 1997. Estimating the crust permeability from fluid-injection-induced seismic emission at the KTB site. Geophysical Journal International 131, F15-F18.

Shapiro, S.A., Rothert, E., Rath, V., Rindschwentner, J., 2002. Characterization of fluid transport properties of reservoirs using induced microseismicity. Geophysics 67, 212-220.

Talwani, P., Chen, L., Gahalaut, K., 2007. Seismogenic permeability, ks. Journal of Geophysical Research: Solid Earth 112(B7). https://doi.org/10.1029/2006JB004665

Vallée, M., Nocquet, J.-M., Battaglia, J., Font, Y., Segovia, M., Regnier, M., Mothes, P., Jarrin, P., Cisneros, D., Vaca, S., 2013. Intense interface seismicity triggered by a shallow slow slip event in the Central Ecuador subduction zone. Journal of Geophysical Research: Solid Earth 118, 2965-2981.

Van der Elst, N.J., Page, M.T., Weiser, D.A., Goebel, T.H., Hosseini, S.M., 2016. Induced earthquake magnitudes are as large as (statistically) expected. Journal of Geophysical Research: Solid Earth 121, 4575-4590.

Vidale, J.E., Shearer, P.M., 2006. A survey of 71 earthquake bursts across southern California: Exploring the role of pore fluid pressure fluctuations and aseismic slip as drivers. Journal of Geophysical Research: Solid Earth 111. 
Wynants-Morel, N., Cappa, F., De Barros, L., Ampuero, J.-P., 2020. Stress Perturbation From Aseismic Slip Drives The Seismic Front During Fluid Injection In A Permeable Fault. Journal of Geophysical Research: Solid Earth 125, e2019JB019179.

Wynants-Morel, N., De Barros, L., Cappa, F., 2021. Sensitivity of the Seismic Moment Released During Fluid Injection to Fault Hydromechanical Properties and Background Stress. Front. Earth Sci. 9. https://doi.org/10.3389/feart.2021.638723

Yeck, W.L., Hayes, G.P., McNamara, D.E., Rubinstein, J.L., Barnhart, W.D., Earle, P.S., Benz, H.M., 2017. Oklahoma experiences largest earthquake during ongoing regional wastewater injection hazard mitigation efforts. Geophysical Research Letters 44, 711-717. 


\section{QAGUPUBLICATIONS}

\section{Journal of Geophysical Research: Solid Earth}

\section{Supporting information for}

\section{Migration of fluid-induced seismicity reveals the seismogenic state of faults}

Louis De Barros ${ }^{1, *}$, Nicolas Wynants-Morel ${ }^{1+}$, Frédéric Cappa $^{1,2}$, Philippe Danré ${ }^{1}$

${ }^{1}$ Université Côte d'Azur, CNRS, Observatoire de la Côte d'Azur, IRD, Géoazur, 06560 Sophia Antipolis, France

${ }^{2}$ Institut Universitaire de France, Paris, France

+ Now at : Institut National de I'Environnement Industriel et des Risques - INERIS, Verneuil-en-Halatte, France

* Corresponding author: debarros@geoazur.unice.fr (Louis De Barros)

\section{Contents of this file}

Text S1

Figures S1 to S4

Table S1

\section{Introduction}

- Figure S1 shows the fault and stress geometry used in the 3DEC computation.

- Table S1 gives the hydro-mechanical parameters of the fault and the surrounding medium used in the 3DEC computation.

- Text S1 describes the fault hydromechanical properties, and the relationships used to compute theoretical diffusivity from the fault aperture.

- Figure S2 shows an example of distance-time plot for synthetic catalog in linear and logarithmic scale, with the fit of the seismic fronts.

- Figure S3 shows the relations between seismic migration and dilation angle.

- Figure S4 complements fig. 5 by showing the distance-time plots for the microseismicity recorded in 5 injection cases (Soultz 1995, 1996, 2000, 2003 and Cooper Basin 2012), with the measured and reconstructed seismic fronts. 


\section{Figure S1}

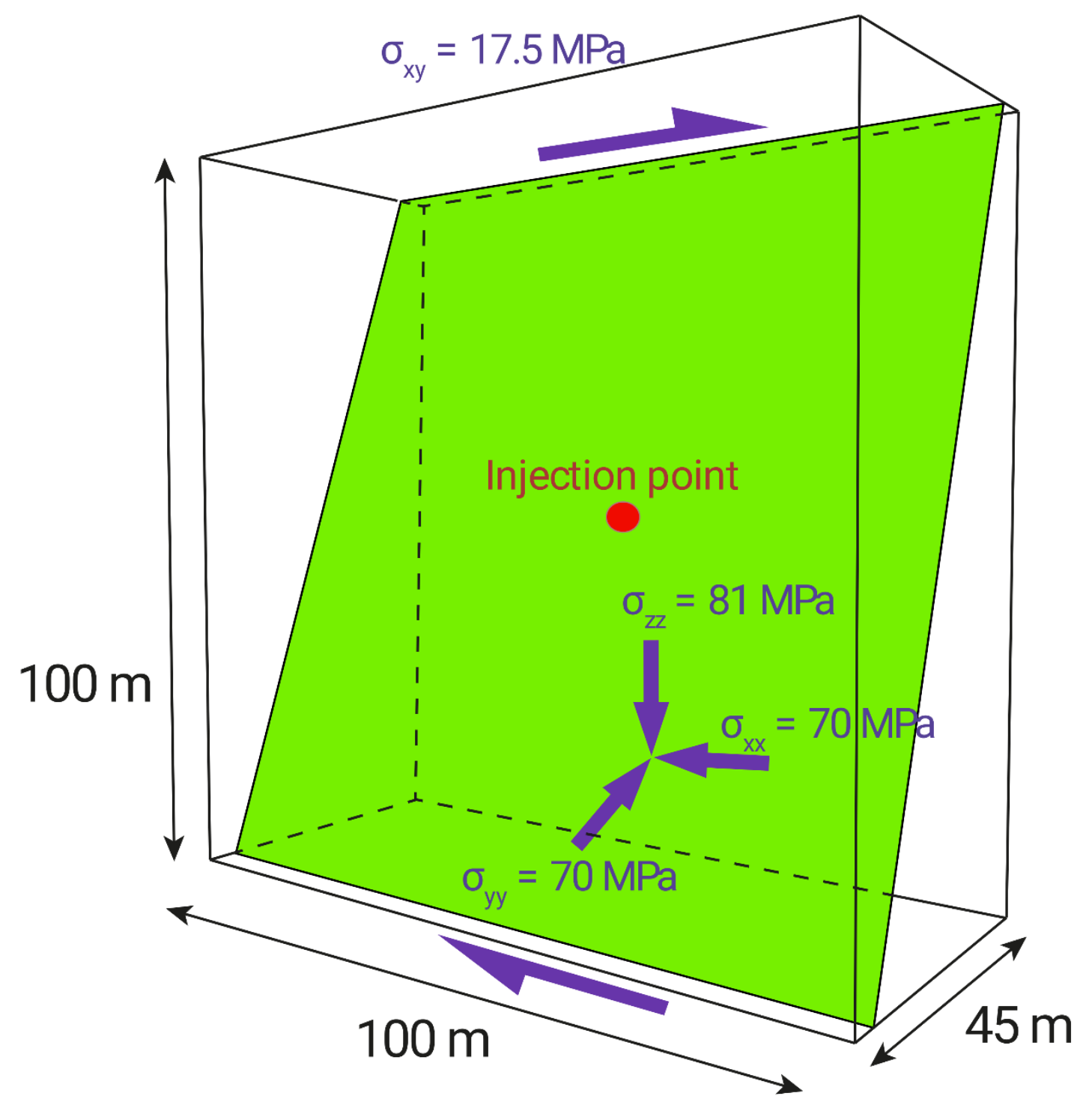

Figure S1:

Figure S1. Model geometry of the $70^{\circ}$ dipping fault within the stress state, modified from Wynants-Morel et al. (2020). The stress state is composed of a vertical $\left(\sigma_{\mathrm{zz}}\right)$ and two horizontal $\left(\sigma_{\mathrm{xx}}\right.$ and $\left.\sigma_{\mathrm{yy}}\right)$ components, plus a deviatoric part $\left(\sigma_{\mathrm{xy}}\right)$ that varies to modify the critical state of the fault. The injection is performed at the center of the fault (red dot). 
Table S1: Model parameters used in the hydro-mechanical modeling.

\begin{tabular}{|c|c|c|}
\hline \multirow{4}{*}{ Rock mechanical properties } & Shear modulus (G) & $15 \mathrm{GPa}$ \\
\hline & Bulk modulus (K) & $25 \mathrm{GPa}$ \\
\hline & Density $(\rho)$ & $2750 \mathrm{~kg} / \mathrm{m}^{3}$ \\
\hline & Permeability & $0 \mathrm{~m}^{2}$ \\
\hline \multirow{2}{*}{ Elastic stiffness of the fault } & Normal stiffness $\left(k_{n}\right)$ & $300 \mathrm{GPa} / \mathrm{m}$ \\
\hline & Shear stiffness $\left(k_{s}\right)$ & $300 \mathrm{GPa} / \mathrm{m}$ \\
\hline \multirow{3}{*}{$\begin{array}{l}\text { Slip-weakening frictional } \\
\text { properties of the fault }\end{array}$} & Static friction $\left(\mu_{s}\right)$ & 0.6 \\
\hline & Dynamic friction $\left(\mu_{d}\right)$ & 0.4 \\
\hline & Critical slip distance $\left(D_{c}\right)$ & $10 \mu \mathrm{m}$ \\
\hline \multirow{5}{*}{$\begin{array}{l}\text { Hydraulic properties of the } \\
\text { fault }\end{array}$} & Initial aperture $\left(b_{h o}\right)$ & $200 \mu \mathrm{m}$ \\
\hline & Initial permeability (k) & $3.3 \times 10^{-9} \mathrm{~m}^{2}$ \\
\hline & Initial diffusivity (D) & $0.2806 \mathrm{~m}^{2} / \mathrm{s}$ \\
\hline & Initial fluid pressure $\left(\mathrm{P}_{0}\right)$ & $30 \mathrm{MPa}$ \\
\hline & Dilation angle $(\Psi)$ & $0^{\circ}$ \\
\hline \multirow{3}{*}{ Fluid properties } & Fluid bulk modulus $\left(\mathrm{K}_{\mathrm{w}}\right)$ & $2 \mathrm{GPa}$ \\
\hline & Fluid density $\left(\rho_{w}\right)$ & $1000 \mathrm{~kg} / \mathrm{m}^{3}$ \\
\hline & Fluid viscosity $\left(\mu_{\mathrm{f}}\right)$ & $10^{-3}$ Pa.s \\
\hline \multirow{3}{*}{ Stress state } & Initial effective normal stress ( $\sigma_{\mathrm{No}}$ ) & $41.3 \mathrm{MPa}$ \\
\hline & Initial shear stress $\left(\tau_{0}\right)$ & $16.8 \mathrm{MPa}$ \\
\hline & $S C U=\tau_{0} / \mu_{s}\left(\sigma_{N 0}-P_{0}\right)$ & $68 \%$ \\
\hline
\end{tabular}

Table S1. Hydro-mechanical parameters used in the 3DEC modelling: elastic properties of the fault and the surrounding rock; frictional and hydraulic properties of the fault; fluid properties and stress state. The parameters highlighted in blue are the ones that varies within the study. The initial aperture varies from 80 to $260 \mu \mathrm{m}$ to allow diffusivity ranging between 0.018 and $0.616 \mathrm{~m}^{2} / \mathrm{s}$ (Fig. 3). The dilation angle is increased up to $8^{\circ}\left(0,1,2,4\right.$ or $\left.8^{\circ}\right)$ to produce Fig. S3. Finally, the initial shear stress varies to get a SCU ranging between $53 \%$ and $72.5 \%$ (Fig. 2). 


\section{Text S1. Fault hydraulic properties: permeability and diffusivity}

In the different synthetic injection tests studied here, the fault has an initial hydraulic aperture $b_{h 0}$ comprised between $80 \mu \mathrm{m}$ and $260 \mu \mathrm{m}$. Assuming a cubic law to model laminar fluid flow between smooth parallel plates (i.e, fault with no roughness) (Witherspoon et al., 1980; Zimmerman and Bodvarsson, 1996), the initial intrinsic permeability " $k$ " is given by:

$$
k=\frac{b_{h}^{2}}{12}
$$

The aperture values assumed here lead to permeability comprised between $5.3 \times 10^{-10}$ and $5.6 \times 10^{-9} \mathrm{~m}^{2}$, respectively.

In the hydromechanical model, the rate of pressure propagation is defined by the hydraulic diffusivity (D, $\left.\mathrm{m}^{2} / \mathrm{s}\right)$ :

$$
D=\frac{T}{S}
$$

where $\mathrm{T}$ is the transmissivity $\left(\mathrm{m}^{2} / \mathrm{s}\right)$ in the modified cubic law for fluid flow in a deformable fault (Witherspoon et al., 1980) and $S$ is the storativity (-):

$$
\begin{gathered}
T=\frac{\rho g}{12 \mu} b_{h}{ }^{3}=\frac{\rho g}{12 \mu}\left(b_{h o}-\frac{\Delta \sigma_{n}^{\prime}}{k_{n}}+\Delta u_{s} \tan \Psi\right)^{3} \\
S=\rho g L\left(\frac{b_{h 0} / s}{K_{w}}+\frac{1}{K+4 / 3 G}\right)
\end{gathered}
$$

with:

$b_{h}=$ hydraulic aperture $(m)\left(b_{h o}=\right.$ initial aperture before injection)

$\mu=$ dynamic viscosity of fluid (Pa.s)

$\mathrm{L}=$ flow path length $(\mathrm{m})$

$\mathrm{g}=$ gravity $\left(\mathrm{m} / \mathrm{s}^{2}\right)$

$\rho=$ fluid density $\left(\mathrm{kg} / \mathrm{m}^{3}\right)$

$\mathrm{s}=$ fault spacing $(\mathrm{m})$ (1 for a single fault)

$\mathrm{K}_{\mathrm{w}}=$ fluid bulk modulus $(\mathrm{Pa})$

$\mathrm{K}=$ rock bulk modulus $(\mathrm{Pa})$

$\mathrm{G}=$ rock shear modulus $(\mathrm{Pa})$

$k_{n}=$ fault normal stiffness $(\mathrm{Pa} / \mathrm{m})$

$\Delta \sigma_{n}^{\prime}=$ change in effective normal stress $(\mathrm{Pa})$

$\Delta \mathrm{u}_{\mathrm{s}}=$ change in shear displacement $(\mathrm{m})$

$\Psi=$ dilation angle $\left({ }^{\circ}\right)$ 
In figure S3, the effect of shear-induced dilation is examined. In the other cases, including the reference case, dilation angle is considered null, thus $\mathrm{T}$ reduces to $\mathrm{T}=\frac{\rho \mathrm{g}}{12 \mu}\left(\mathrm{b}_{\mathrm{ho}}-\frac{\Delta \sigma_{\mathrm{n}}^{\prime}}{\mathrm{k}_{\mathrm{n}}}\right)^{3}$. Therefore, in all cases, hydromechanical coupling influences the evolution of transmissivity, and consequently, the diffusivity.

At the initial stage, before the injection starts, the initial hydraulic diffusivity can be estimated using the reference parameters listed in table S1 (supplementary material). Before the injection starts, there is no changes in effective normal stress $\left(\Delta \sigma_{n}^{\prime}=0 \mathrm{~Pa}\right)$ and shear displacement $\left(\Delta \mathrm{u}_{\mathrm{s}}=0 \mathrm{~m}\right)$. For the reference case, $\mathrm{b}_{\mathrm{ho}}=200 \mu \mathrm{m}$. We then obtain initial values of transmissivity of $\mathrm{T}=6.54 \times 10^{-6} \mathrm{~m}^{2} / \mathrm{s}$ and storativity of $\mathrm{S}=2.3303$ $\times 10^{-5}$, leading to an apparent hydraulic diffusivity of $0.2806 \mathrm{~m}^{2} / \mathrm{s}$ over the fault for the reference case.

Then, we tested different values of initial hydraulic apertures, $80,110,145$ and $260 \mu \mathrm{m}$ in figure 3 . The resulting transmissivity, storativity and diffusivity are summarized in table $\mathbf{S} 2$.

\begin{tabular}{|c|c|c|c|c|}
\hline $\begin{array}{c}\text { Hydraulic } \\
\text { aperture } \mathrm{b}_{\mathrm{h}}(\mu \mathrm{m})\end{array}$ & $\begin{array}{c}\text { Permeability k } \\
\left(\mathrm{m}^{2}\right)\end{array}$ & $\begin{array}{c}\text { transmissivity T } \\
\left(\mathrm{m}^{2} / \mathrm{s}\right)\end{array}$ & $\begin{array}{c}\text { Storativity S } \\
)\end{array}$ & $\begin{array}{c}\text { Diffusivity D } \\
\left(\mathrm{m}^{2} / \mathrm{s}\right)\end{array}$ \\
\hline 80 & $5.33 \times 10^{-10}$ & $4.185 \times 10^{-7}$ & $2.3241 \times 10^{-5}$ & 0.0180 \\
\hline 110 & $1.00 \times 10^{-9}$ & $1.088 \times 10^{-6}$ & $2.3256 \times 10^{-5}$ & 0.0468 \\
\hline 145 & $1.75 \times 10^{-9}$ & $2.492 \times 10^{-6}$ & $2.3275 \times 10^{-5}$ & 0.1071 \\
\hline $\mathbf{2 0 0}$ & $\mathbf{3 . 3 3 \times 1 0 ^ { - 9 }}$ & $\mathbf{6 . 5 4 \times 1 0 ^ { - 6 }}$ & $\mathbf{2 . 3 3 0 3 \times 1 0 ^ { - 5 }}$ & $\mathbf{0 . 2 8 0 6}$ \\
\hline 260 & $5.63 \times 10^{-9}$ & $1.43 \times 10^{-5}$ & $2.3335 \times 10^{-5}$ & 0.6157 \\
\hline
\end{tabular}

Table S2. Hydraulic aperture, permeability, transmissivity, storativity and diffusivity used in the models to build figure 3. The reference values are highlighted in bold.

The different values of initial hydraulic apertures, from 80 to $260 \mu \mathrm{m}$ in figure 3, give diffusivities ranging between 0.018 and $0.616 \mathrm{~m}^{2} / \mathrm{s}$, respectively. Therefore, these values are within the conventional range $(0.01$ and $10 \mathrm{~m} / \mathrm{s}^{2}$ ) estimated from the analysis of seismic migration (e.g., Parotidis et al., 2003; Shapiro et al., 2002; Talwani et al., 2007) and measured in-situ with high-pressure injection testing on fractures (Rutqvist et al., 1998).

The diffusivity then evolves with the injected fluid pressure and associated mechanical deformation. For the reference case, at the pressure front, fluid pressure has increased of approximately $0.3 \mathrm{MPa}$ from its initial values, and the mechanical aperture varies of $1 \mu \mathrm{m}$, proportionally to the pressure variation. This results in a small increase in $D$ from 0.2806 to $0.2849 \mathrm{~m}^{2} / \mathrm{s}$ at the pressure front. A small increase of $D$ is also observed for the other tested values of initial hydraulic apertures, giving a range of diffusivity between 0.0187 to 0.6229 $\mathrm{m}^{2} / \mathrm{s}$ after the start of pressure increase at the front. 


\section{Figure S2}
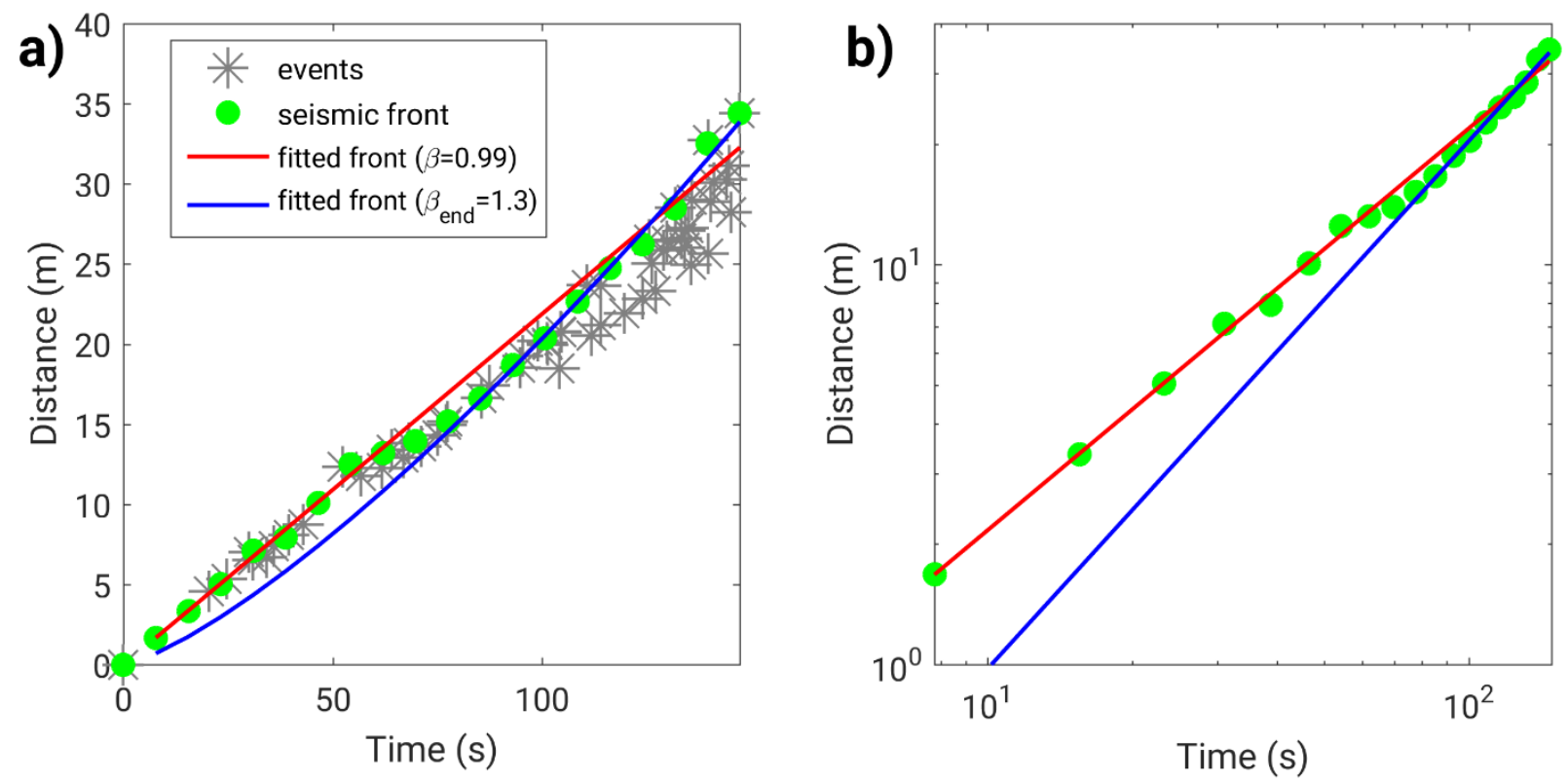

Figure S2. Distance-time plot for the synthetic events (gray stars) induced by an injection in a fault with $\mathrm{SCU}=68 \%$. Panel a) has linear scales, while panel b) also shows distance-time relations, but with logarithmic scales. In both panels, the green points show the reconstructed seismic front. The red and blue lines are the best fitting lines with slope of $\beta$ or $\beta_{\text {end }}$ in b), when considering all points, or only the second half-period, respectively. 


\section{Figure S3}
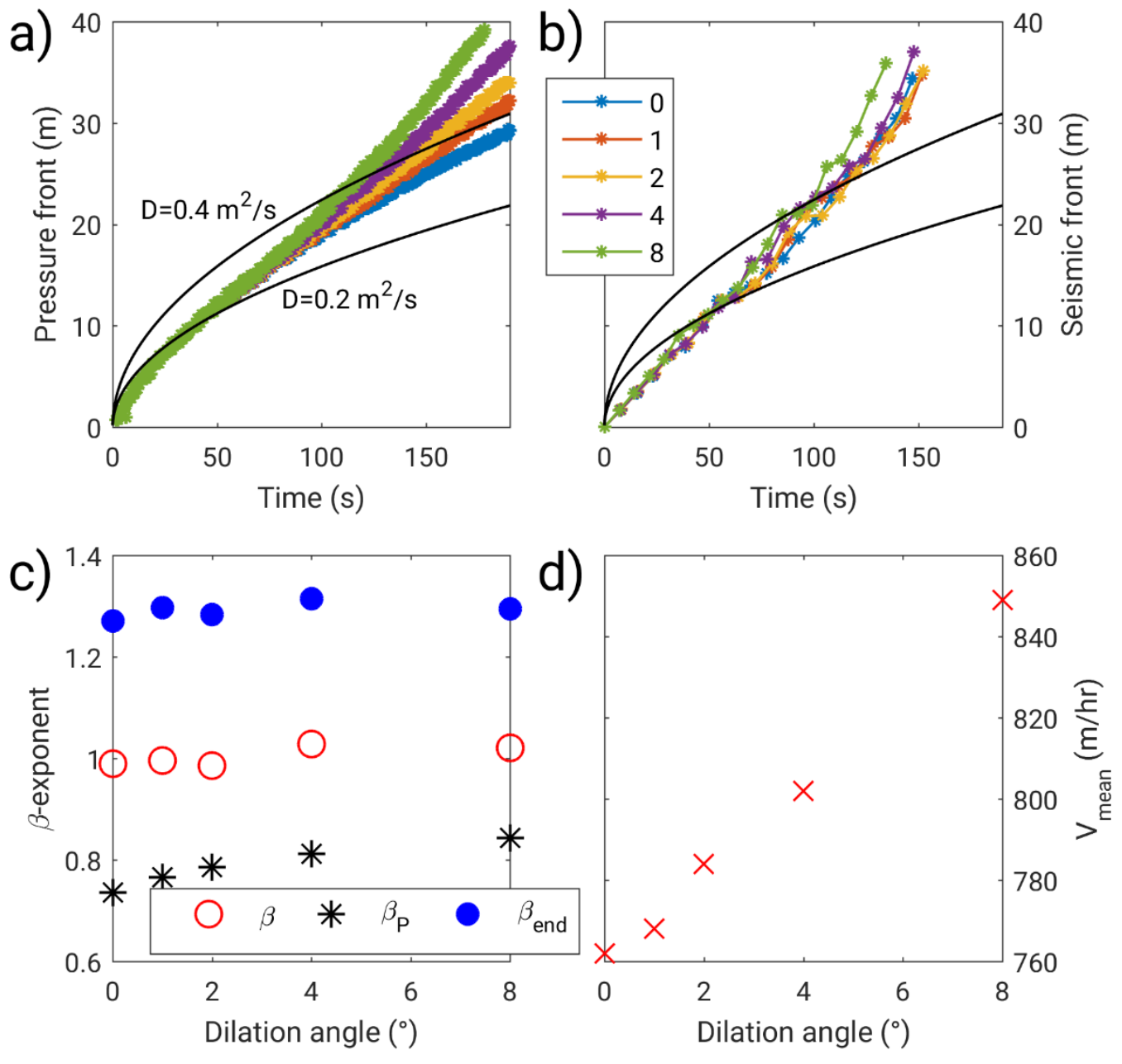

Figure S3. Relation between pressure front, seismic migration and dilatancy angle. Distance-time plots for a) the overpressure front (defined as $1 \%$ of the initial hydrostatic pressure) and b) the reconstructed seismic front, which is also the aseismic front. In both a) and b), results are colored according to the permeability. For sake of reference, the black lines show the theoretical curve (eq. 1) for hydraulic diffusivity of $D=0.2$ and 0.4 $\mathrm{m}^{2} / \mathrm{s}$. c) Exponent $\beta$ measured on the pressure front $\left(\beta_{\mathrm{P}}\right)$, on the beginning and on the second half of the seismic front ( $\beta$ and $\beta_{\text {end }}$, respectively), with respect to the dilatancy angle. $d$ ) Mean migration velocity $\left(V_{\text {mean }}\right)$ with respect to the dilatancy angle. 
Author version

Published in Journal of Geophysical Research - Solid Earth,

Doi: 10.1029/2021JB022767

\section{Figure S4}
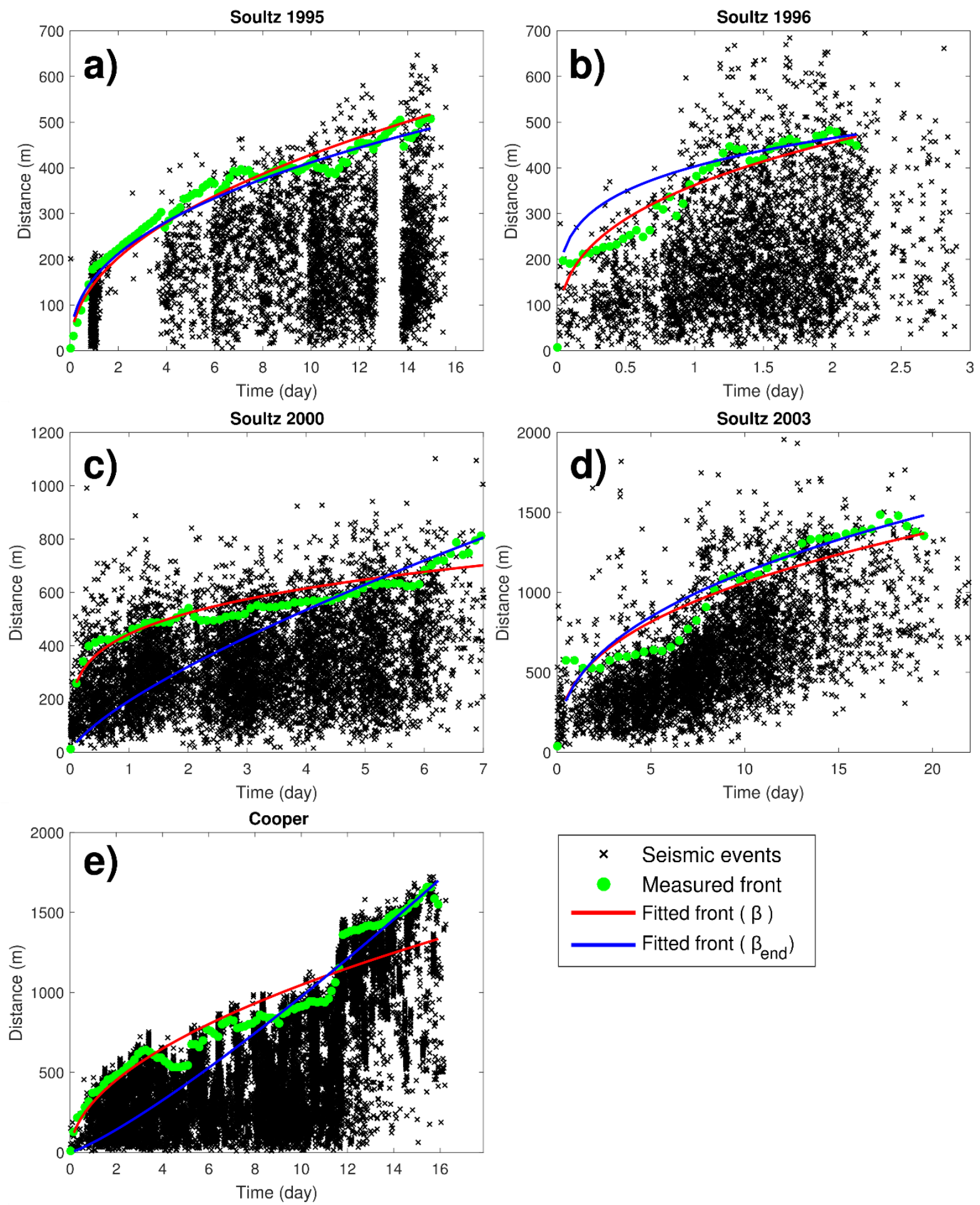

Figure S4. Seismic migration, displayed as distance-time plot, observed in the geothermal fields of (a) Soultzsous-Forêts, France, 1995 (Gerard et al., 1997; GEIE EMC \& EOST, 2019a), (b) Soultz-sous-Forêts, France, 1996, (Gerard et al., 1997; GEIE EMC \& EOST, 2019b), (c) Soultz-sous-Forêts, France, 2000 (Cuenot et al., 2008; GEIE EMC \& EOST, 2018), (d) Soultz-sous-Forêts, France, 2003, (Calò and Dorbath, 2013; EOST \& GEIE EMC, 2018) 
(e) Cooper Basin, Australia, 2012 Australia, 2012, (Baisch et al., 2015; IS EPOS, 2020). This figure complements Figure 5 in the main text. In all cases, the green dots show the reconstructed seismic front. The red and blue

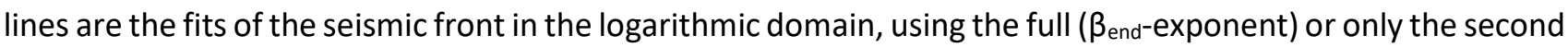
half ( $\beta_{\text {end }}$-exponent) of the sequence, respectively.

\section{References:}

Calò, M., Dorbath, C., 2013. Different behaviours of the seismic velocity field at Soultz-sous-Forêts revealed by 4-D seismic tomography: case study of GPK3 and GPK2 injection tests. Geophysical Journal International 194, 1119-1137.

Cuenot, N., Dorbath, C., Dorbath, L., 2008. Analysis of the microseismicity induced by fluid injections at the EGS site of Soultz-sous-Forêts (Alsace, France): implications for the characterization of the geothermal reservoir properties. Pure and Applied Geophysics 165, 797-828.

EOST \& GEIE EMC, 2018. Episode: 2003 stimulation Soultz-sous-Forêts [Collection]. EOST - CDGP. https://doi.org/10.25577/SSFS2003

GEIE EMC \& EOST, 2019a. Episode: 1995 Stimulation and Hydraulic Tests Soultz-sous-Forêts. EOST-CDGP. https://doi.org/10.25577/SSFS1995

GEIE EMC \& EOST, 2019b. Episode: 1996 Stimulation and Hydraulic Tests Soultz-sous-Forêts. EOST-CDGP. https://doi.org/10.25577/SSFS1996

GEIE EMC \& EOST, 2018. Episode: 2000 stimulation Soultz-sous-Forêts. [Collection]. EOST - CDGP. https://doi.org/10.25577/SSFS2000

Gerard, A., Baumgärtner, J., Baria, R., \& Jung, R., 1997. An attempt towards a conceptual model derived from 1993-1996 hydraulic operations at Soultz. In Proc. NEDO Internat. Symp. Sendai, Japan. 2, pp. 329-341

Parotidis, M., Rothert, E., Shapiro, S.A. (2003). Pore-pressure diffusion: A possible triggering mechanism for the earthquake swarms 2000 in Vogtland/NW-Bohemia, central Europe. Geophysical Research Letters 30. https://doi.org/10.1029/2003GL018110

Rutqvist J., Noorishad J., Tsang C-F. (1998), Determination of fracture storativity in hard rocks using high-pressure injection testing, Water Resources Research, 34(10), 2551-2560

Shapiro, S.A., Rothert, E., Rath, V., Rindschwentner, J. (2002). Characterization of fluid transport properties of reservoirs using induced microseismicity. Geophysics 67, 212-220.

Talwani, P., Chen, L., and Gahalaut, K. (2007), Seismogenic permeability, ks, J. Geophys. Res., 112, B07309, https://doi.org/10.1029/2006JB004665.

Wynants-Morel, N., Cappa, F., De Barros, L., Ampuero, J.-P., 2020. Stress Perturbation From Aseismic Slip Drives The Seismic Front During Fluid Injection In A Permeable Fault. Journal of Geophysical Research: Solid Earth 125, e2019JB019179.

Zimmerman, R.W., Bodvarsson, G.S., 1996. Hydraulic conductivity of rock fractures. Transp. Porous Media 23, 1-30. 